\title{
1 Heparanase-2 protects from endothelial injury by inhibiting TLR4 signaling
}

3 Running title: Heparanase 2 protects from microvascular injury

4

5 Yulia Kiyan ${ }^{1}$, PhD; Sergey Tkachuk ${ }^{1}, P h D ;$ Kestutis Kurselis ${ }^{2}$, MS; Nelli Shushakova ${ }^{3}, P h D$;

6 Klaus Stahl ${ }^{l}$, MD; Damilola Dawodu ${ }^{1}, P h D ;$ Roman Kiyan ${ }^{2}, P h D ;$ Boris Chichkov ${ }^{2}$, PhD;

$7 \quad$ Hermann Haller ${ }^{1 *}, M D$

8

\section{Affiliations}

$10{ }^{l}$ Department of Nephrology, Hannover Medical School, Hannover, Germany

$11{ }^{2}$ Institute for Quantum Optics, Leibniz University Hannover, Hannover, Germany

$12{ }^{3}$ Phenos GmbH, Hannover, Germany

13 *Contact:

14 Dr. Yulia Kiyan

15 Clinic for Nephrology, Hannover Medical School

16 Carl Neuberg-Strasse 1

1730625 Hannover

18 e-mail: kiian.ioulia@mh-hannover.de

19 Tel: $+49(0) 5115322715$

20 Fax: $+49(0) 5115322713$ 
1 Keywords: endothelial cells; glycocalyx; inflammation

2 Subject codes: Cell signaling/Signal Transduction; Vascular Disease; Inflammation

3 Word count: 6827

4 Total number of figures and tables: 7

5 TOC category: Basic

6 TOC subcategory: Arteriosclerosis, Thrombosis, and Vascular Biology 


\section{Abstract}

2 Objective. The endothelial glycocalyx and the regulation of its shedding are important to

3 vascular health. Endo- $\beta$-D-glucuronidase heparanase-1 (HPSE1) is the only enzyme that can

4 shed heparan sulfate. However, the mechanisms are not well understood.

5 Approach and results. To investigate HPSE1 and its endogenous inhibitor, heparanase-2

6 (HPSE2), we used cell culture, lentiviral protein overexpression, a microfluidic chip model of

7 cell culture under shear stress conditions, and lipopolysaccharide (LPS) injections in mice.

8 We show that HPSE1 activity aggravated Toll-like receptor 4 (TLR4)-mediated response of

9 endothelial cells to LPS. On the contrary, HPSE2 overexpression was protective. The

10 microfluidic chip flow model confirmed that HPSE2 prevented heparan sulfate shedding by

11 HPSE1. Furthermore, heparan sulfate did not interfere with cluster of differentiation-14

12 (CD14)-dependent LPS binding, but instead reduced the presentation of the LPS-CD14

13 complex to TLR4. HPSE2 reduced LPS-mediated TLR4 activation by LPS, subsequent cell

14 signaling, and cytokine expression. Moreover, HPSE2-overexpressing endothelial cells

15 remained protected against LPS-mediated loss of cell-cell contacts. In vivo, expression of

16 HPSE2 in plasma and kidney medullary capillaries was decreased in mouse sepsis model. We

17 next applied purified HPSE2 in mice and observed decreases in TNF $\alpha$ and IL-6 plasma

18 concentrations after intravenous LPS injections.

19 Conclusions. Our data demonstrate the important role of heparan sulfate and the glycocalyx

20 in endothelial cell activation and suggest a protective role of HPSE2 in microvascular

21 inflammation. HPSE2 offers new options for protection against HPSE1-mediated endothelial

22 damage and preventing microvascular disease. 


\section{Graphical abstract}

\section{Quiescent endothelium}

HS chains regulate TLR4 activation

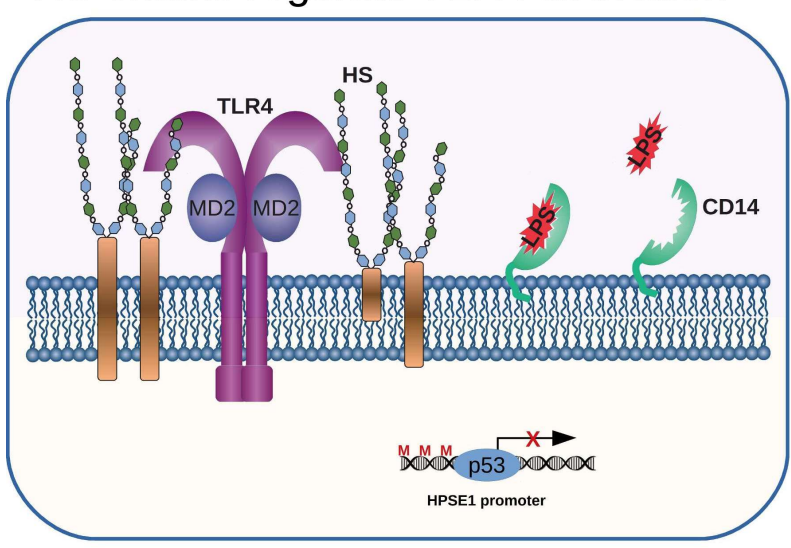

\section{Activated endothelium}

HS chains are cleaved by HPSE1

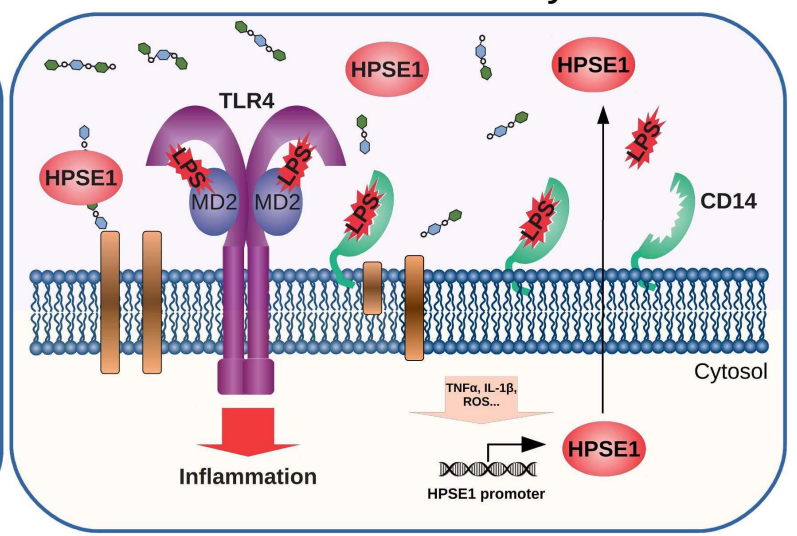

\section{HPSE2 treated endothelium}

HS chains are protected by HPSE2

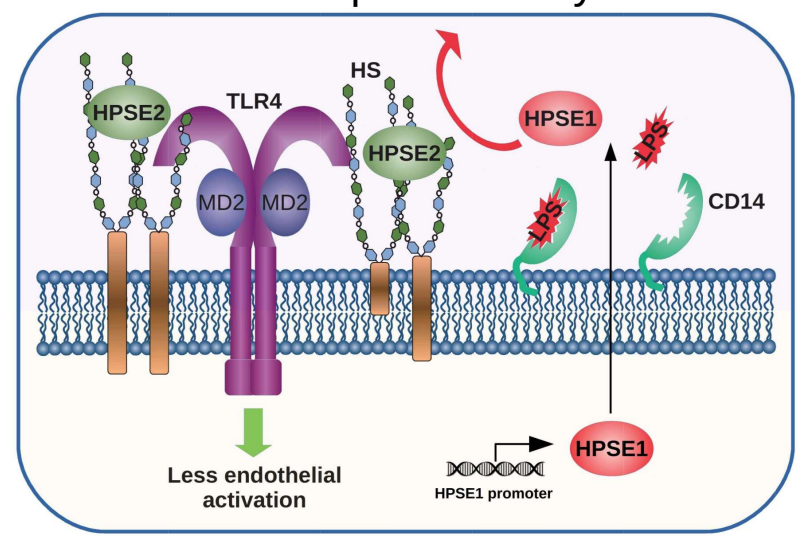

\section{Non standard abbreviations}

\begin{tabular}{|l|l|}
\hline HPSE1 & Heparanase 1 \\
\hline HPSE2 & Heparanase 2 \\
\hline LPS & Lipopolysaccharide \\
\hline TLR4 & Toll-like receptor 4 \\
\hline CD14 & Cluster of differentiation 14 \\
\hline PDMS & Polydimethylsiloxan \\
\hline CLP & Cecal ligation and puncture \\
\hline
\end{tabular}




\section{Introduction}

The endothelial glycocalyx comprises a network of core proteins and branching

3 glycosaminoglycan polymers such as heparan sulfate, chondroitin sulfate, and hyaluronans,

4 that cover the luminal side of endothelial cells. The glycocalyx is essential to maintain

5 integrity and function of the endothelial layer ${ }^{1-3}$. It serves as a receptor or co-receptor for

6 various ligands such as growth factors, cytokines and chemokines, coagulation factors,

7 proteases, complement-system proteins, membrane receptors, and adhesion proteins ${ }^{4}$.

8 Endothelial glycocalyx shedding occurs during many pathological conditions ${ }^{5}$, including

9 cardiovascular, renal diseases ${ }^{6,7}$ and $\operatorname{sepsis}^{8-10}$. Heparan sulfate is a highly sulfated

10 polysaccharide element of the endothelial glycocalyx. Experiments in gene-deleted mice

11 showed that glycocalyx disturbances are not compatible with life. ${ }^{11,12}$. The heparan sulfate

12 interactome is formed by a 300-protein network ${ }^{4}$. Thus, degradation of heparan sulfate affects

13 numerous cellular functions. The only known endo- $\beta$-D-glucuronidase capable of degrading

14 heparan sulfate chains in mammals is heparanase 1 (HPSE1). HPSE1 is upregulated in many

15 inflammatory diseases including cancer ${ }^{13}$, diabetes ${ }^{14}$, and sepsis ${ }^{10}$.

17 reports addressed the role of heparan sulfate in the TLR4-mediated response. Soluble heparan

18 sulfate chains serve as TLR4 ligands ${ }^{16,17}$. Cleavage of heparan sulfate by HPSE1 strongly

19 promoted TLR4 response in macrophages ${ }^{18}$. Furthermore, TLR4 signaling was inhibited in

20 cells cultured on heparan sulfate proteoglycans-rich matrix. This inhibition was relieved by

21 the matrix degradation ${ }^{19}$. However in microglia, overexpression of HPSE1 led to diminished

22 LPS-induced response ${ }^{20}$. Co-localization of TLR4 co-receptor Cluster of Differentiation 14

23 (CD14) with heparan sulfate has been observed that let the authors to suggest that heparan 
1 sulfate promotes TLR4/CD14 association. In addition, it has been demonstrated that HPSE1

2 can act via TLRs causing pro-inflammatory response that is independent of catalytic

3 activity $^{16,21}$.

4 McKenzie and colleagues cloned and characterized the Heparanase 2 (HPSE2)

5 protein, that exhibits a $40 \%$ homology to HPSE $1^{22}$. HPSE2 has no catalytic activity, but

6 instead can inhibit HPSE ${ }^{23}$. An antagonistic interaction of the heparanases in cancer have

7 been recently reviewed recently ${ }^{24}$. Although HPSE2 circulates in the human plasma ${ }^{13}$,

8 interactions between HPSE1 and HPSE2 in endothelial cells has not been investigated.

9 Endothelial cells express HPSE1 in vitro ${ }^{25,26}$ and serve as an important local source of

10 HPSE1during inflammation ${ }^{27}$. We studied HPSE1 and HPSE2 in endothelial cells and animal

11 models to elucidate the role of these enzymes in maintaining endothelial integrity

\section{Materials and methods.}

\section{1. Cells, antibody, Real Time-PCR.}

14 Human microvascular endothelial cells line HMEC-1 was from ATCC. Cells were cultured

15 as recommended by the supplier. Primary human dermal microvascular endothelial cells were

16 from Promocell. Cells were cultivated as recommended by the supplier and used in the

17 passage 4. Unless otherwise indicated, HMEC-1 cells were used through the study. The

18 following antibodies were used: Heparan sulfate (clone 10e4) from Amsbio; HPSE1

19 (GTX32650) from GeneTex; Heparanase 2 (NBP1-31457) from Novus Biologicals were used

20 for western blotting; 1c7 monoclonal blocking antibody to HPSE2 was a kind gift of Prof. I.

21 Vlodavsky; antibodies to HPSE2 purchased from Sigma (Cat. \# HPA044603) were used for

22 tissue staining; Tubulin (556321) from BD Pharmingen, P-p65 (93H1); P-p38 (D3F9), P-

23 MEK (166M8), and cleaved Caspase 3 antibody (9665) were from Cell Signaling 
1 Technologies; VE-cadherin antibody (Clone 123413) from R\&D Systems; mouse CD31

2 Dianova (Dia-310) were used for tissue staining; phalloidin (Alexa 488) was from Invitrogen.

3 DraQ5 was from BioStatus Ltd. OGT 2115 was from Tocris. Purified heparan sulfate (10-70

$4 \mathrm{kDa}$ ) was from Sigma. Bovine fibronectin was from Sigma. Purified catalytically active

5 HPSE1 was from R\&D Systems.

6 Cells proliferation was assessed by BrdU Cell proliferation ELISA from Roche. IL-6 ELISA

7 was from Affimetrics. Western blotting was performed as established earlier ${ }^{28}$. Dot blot was

8 performed using nitrocellulose membrane and Heparan sulfate (clone 10e4).

9 RNA was isolated from cells using Quiagen RNAeasy kits. RT-PCR Taqman assay was

10 performed using Roche TaqMan Master Mix and Roche LightCycler96. The sequence of the

11 primers is given in the Supplementary Table 1. TaqMan Gene Expression Assays for

12 RANTES, IFNB1, and actin as a housekeeper were from Thermofisher Scientific. Human

13 Common Cytokine $\mathrm{RT}^{2}$ profiler array (Quiagen) was used accordingly to manufacturer's

14 instructions. TMB substrate kit was from Thermofisher Scientific.

\section{3. Lentivirus for HPSE2 and HPSE1 overexpression.}

16 Construction of the expression vectors was performed according to the standard cloning

17 protocols. The vectors were generated by recombination of pDEST12.2 (Invitrogen) with

18 vectors containing full length HPSE2 and HPSE1 (pENRT223.1_HPSE1,

19 pENRT223.1_HPSE2, MyBioSourse, San Diego, CA, USA). Gateway LR Clonase enzyme

20 mix (Invitrogen) catalysis the in vitro recombination between an entry clone

21 pENTR223.1_HPSE2 and destination vector pDEST12.2 to generate expression clones.

22 Correct clones was selected by PstI (New England Biolabs) digestion and confirmed by

23 sequencing (SeqLab). For all cloning experiments in current work subcloning efficiency DH5 
1 alpha competent cells (Invitrogen) were used accordingly to the standard protocols

2 recommended by the supplier.

\section{4. Lentiviral gene transfer of HPSE2 and HPSE1.}

4 Briefly, the lentivirus packaging genome $\mathrm{pCMV}-\mathrm{dR} 8.74^{29}$, and $\mathrm{pMG} 2 \mathrm{G}$ vectors were kindly

5 provided by Dr. Didier Trono (Department of Genetics and Microbiology, Faculty of

6 Medicine, University of Geneva, Switzerland). The lentivirus transfer vector used in this

7 study was generated by Gateway cloning strategy (Invitrogen). An entry vector pENRT223.1

8 HPSE2 (MyBioSourse) was used. As Gateway Destination vector was used modified plasmid

9 pWPTS-GFP (Tronolab). Modification plasmid pWPTS-GFP was performed by Gateway

10 Vector Conversion System (Invitrogen). A Gateway cassette containing attR recombination

11 sites flanking ccdB gene and a chloramphenicol-resistance gene are blunt-end cloned into

12 cloning site pWPTS-GFP to generate a pWPTS-Dest vector. Gateway LR Clonase enzyme

13 mix (Invitrogen) carried over the in vitro recombination between an entry clone pENTR-

14 HPSE2 and destination vector pWPTS-Dest to generate expression clones pWPTS-HPSE2.

15 pCMV-dR8.74, pMD2G and pWPTS-HPSE2 plasmids were purified using an EndoFree ${ }^{\circledR}$

16 Plasmid Maxi kit (Qiagen, Valencia, CA), and co-transfected (using ratio pWPTS-

17 HPSE2:pCMV-dR8.74:pMD2G = 3:2:1) into 293T cells using PerFectin transfection reagent

18 (Genlantis) as per manufacturer. After $48 \mathrm{~h}$ post transfection cell supernatants, containing

19 viral particles, were filtered using $0.4 \mathrm{~mm}$ Steriflip vacuum filtration system (Millipore) and

20 concentrated by ultracentrifugation at $50000 \mathrm{~g}$ for $1.5 \mathrm{~h}$ at $4{ }^{\circ} \mathrm{C}^{30}$. Viral titer was determined

21 by LV Lentiviral Titer kit (MoBiTec) and viruses where used at a Multiplicity of infection of

221 - 5 using polybrene (H9268, Sigma) at a concentration of $2 \mu \mathrm{g} / \mathrm{ml}$.

\section{5. Microfluidic experiments.}


2 Dow Corning) by replication of the polymeric master. The master was produced at the

3 Institute for Quantum Optics, Leibniz University (Hannover) from diurethane dimethacrylate

4 resin (Sigma-Aldrich) by two-photon polymerization (2PP) technology ${ }^{31}$ The chips consisted

5 of 4 parallel $10 \mathrm{~mm}$-long and $2 \mathrm{~mm}$-wide channels. The height of the channels was $1 \mathrm{~mm}$.

6 PDMS-microfluidic chips were sealed with $150 \mu \mathrm{m}$ thick microscopy cover glass using

7 plasma bonding ${ }^{32}$. The diameter of the chip was matched to $35 \mathrm{~mm}$ diameter of the cover

8 glass for compatibility with the Okolab incubation chamber.

10 microfluidic actuation platform was built on the basis of Okolab BOLD LINE H301BL stage

11 incubation set, 4-channel 400VDL/VM4 OEM peristaltic pumps (Watson-Marlow GmbH).

12 Equipment integrated into system provided incubation of the Chips, liquids circulation

13 through the chip, loading/extraction of the cultured cells and loading specific chemicals for

14 experiments. The operation of the microfluidic actuation platform was computer-controlled.

15 The microfluidic interface was based on standard Teflon ${ }^{\circledR}$ tubes with outside diameter of

$161.8 \mathrm{~mm}$ and standard Omni-Lok ${ }^{\circledR}$ microfluidic connectors (Diba Industries Inc.).

18 fibronectin to facilitate cell adhesion. Control virus-transduced cells were seeded in 2

19 channels of the chip; whereas the other two channels were seeded with HPSE2-

20 overexpressing HMEC-1 cells. Thus, identical experimental conditions were provided for

21 both cell variants. Cells were allowed to adhere for 2-3 hrs, after that the medium flow was

22 initiated in all four channels. Medium flow rate was used form $0.4 \mathrm{ml} / \mathrm{h}$ that corresponded to

$230.1 \mathrm{dyn} / \mathrm{cm}^{2}$ shear stress to $159 \mathrm{ml} / \mathrm{h}$ that corresponded to $38.75 \mathrm{dyn} / \mathrm{cm}^{2}$. Cells were

24 incubated under flow conditions for 3 days before the experiments. Purified active HPSE1 
1 was perfused through the channels for $4 \mathrm{hrs}$. Cells were fixed by perfusion with $2 \%$ PFA and

2 then stained.

3 Confocal microscopy was performed using Leica TCS-SP2 AOBS confocal microscope

4 (Leica Microsystems). All the images were taken with oil-immersed x63 objective, NA 1.4.

5 Series of z-scans were processed and quantified using ImageJ software.

\section{6. Biotin-LPS binding and pull-down assay.}

7 Ultrapure biotin-LPS that activates only TLR4 pathway was purchased from InVivoGen. To

8 analyze LPS binding, cells were placed on ice to prevent receptor internalization and

9 incubated with 50ng/ml biotin-LPS for $1 \mathrm{~h}$. Then cells were washed three times with $1 \%$ BSA

10 in PBS and incubated with streptavidin-conjugated HRP on ice for $1 \mathrm{~h}$. HRP activity was

11 quantified using TMB substrate kit. Measurements were take using Tecan plate reader.

12 For pull down assay strepavidin-magnetic beads were used. Cells were incubated on ice with

$1350 \mathrm{ng} / \mathrm{ml}$ biotin-LPS. Then, the cells were placed at $37^{\circ} \mathrm{C}$ for indicated time to allow for

14 activation of TLR4 signaling complex. Then cells were placed on ice, washed, and cell lysis

15 was performed. Cell lysates were incubated with streptavidin-beads for $1 \mathrm{~h}$ at $4^{\circ} \mathrm{C}$ on rotator,

16 then washed three times with ice cold PBS and used for electrophoresis followed by

17 immunoblotting.

18 7. Cell surface TLR4 ELISA.

19 Cell surface TLR4 expression was measured on live cells incubated on ice in buffer

20 containing $0.5 \% \mathrm{BSA} / \mathrm{PBS}$ with $0.05 \% \mathrm{NaN}_{3}$ in ELISA plate ${ }^{33}$. Staining was quantified using

21 HRP-antibody and TMB substrate kit.

\section{8. Immunocytochemistry.}


1 After the stipulated time, cells grown on coverslips were fixed and processed for

2 immunostaining as we have previously described ${ }^{34}$. Briefly, cells were stained for with alexa

3 fluor 488 phalloidin (ThermoFisher Scientific) and subsequently for VE-Cadherin or heparan

4 sulfate. The corresponding secondary antibody conjugated with alexa fluor 594 for 1 hour at

5 room temperature. DAPI was applied for nuclear staining. For negative controls, samples

6 were incubated with mouse IgG. Cells were then mounted with Aqua poly mount

7 (Polysciences) and analyzed on a Leica TCS-SP2 AOBS confocal microscope (Leica

8 Microsystems). All the images were taken with oil-immersed x40 objective, NA 1.25 and x63

9 objective, NA 1.4.

\section{9. HPSE2 purification.}

11 HPSE2 was purified from conditioned medium of HEK 293T cells infected with HPSE2-

12 overexpression lentivirus. Conditioned medium was collected, centrifuged at $3500 \mathrm{rpm}$ for 10

$13 \mathrm{~min}$, and filtered through $0.22 \mu \mathrm{m}$ filter. HPSE2 was collected with flow-through from

14 CaptoQ ion exchange column equilibrated with $20 \mathrm{mmol} / \mathrm{L}$ Tris $\mathrm{pH}$ 8.7. HPSE2-containing

15 fractions were collected, buffer was changed to $20 \mathrm{mmol} / \mathrm{L}$ MES pH 6.0 containing 100

$16 \mathrm{mmol} / \mathrm{L} \mathrm{NaCl}$. HPSE2 was elute with $0.1-1 \mathrm{~mol} / \mathrm{L} \mathrm{NaCl}$ gradient. HPSE2 fractions purity

17 was assessed by electrophoresis followed by gel staining with Colloidal Blue Staining Kit

18 (ThermoFisher Scientific) and by western blotting. HPSE2 was collected, concentrated using

19 centricons, and dialysed against PBS.

\section{10. Animal experiments.}

21 Sepsis models in mice. All procedures were carried out at Phenos GmbH (Hannover,

22 Germany) The animal protection committee of the local authorities (Lower Saxony state

23 department for food safety and animal welfare [LAVES]) approved all experiments 
1 (approval: 33.19-42502-04-16/2255). The group size was determined using

$2 \mathrm{http}: / /$ powerandsamplesize.com/ to achieve a detectable difference between different groups with

3 an $80 \%$ probability at a 5\% significance level. Eight- to 10 -weeks-old male C57BL6 mice (20-25

4 g) obtained from Charles River (The Charles River Laboratories; Sulzfeld, Germany) were

5 injected iv with purified HPSE2 $(5 \mu \mathrm{g} / \mathrm{g}$ body weight) and immediately thereafter low dose (5

$6 \mathrm{ng} / \mathrm{g}$ body weight) of LPS (E.coli O111:B4, Sigma) administration was performed by iv

7 injection. This LPS dose was chosen in preliminary experiments ranging from 5 to $1000 \mathrm{ng} / \mathrm{g}$

8 body weight. $5 \mathrm{ng} / \mathrm{g}$ body weight LPS dose was well tolerated and resulted in a transient

9 increase of pro-inflammatory cytokine level in blood within 2-4h after injection which

10 declines at $8 \mathrm{~h}$ and completely normalized at $20 \mathrm{~h}$ post injection (data not shown). The blood

11 sample were obtained at $2 \mathrm{~h}$ post LPS injection, the plasma levels of pro-inflammatory

12 cytokines IL-6 and TNF $\alpha$ were quantified by bead-based flow cytometry assay (CBA Kit; BD

13 Biosciences, Heidelberg, Germany) according to the manufacturer's instructions.

14 Polymicrobial sepsis in mice was induced by cecal ligation and puncture (CLP) as described

15 previously $^{35}$. Vehicle (PBS) or purified HPSE2 (100 $\mu \mathrm{g}$ in $\left.50 \mu \mathrm{l}\right)$ was administrated by

16 intravenous injection $1 \mathrm{~h}$ prior to CLP surgery. At $18 \mathrm{~h}$ after CLP or sham operation, mice

17 were anesthetized with isofluorane for blood sampling. Subsequently animals were sacrificed

18 and the kidneys were perfused with PBS solution via the left ventricle, removed, fixed in

19 formalin for $24 \mathrm{~h}$, and processed for immunohistochemistry as described ${ }^{35}$.

20 11. Statistics. We used mean \pm SEM throughout this study. All experiments were repeated

21 independently at least three times. For comparing two different groups of data, Student's T

22 test test was applied. Multiple comparisons were analyzed by using the one-way analysis of

23 variance with the Tukey as a post hoc test. "*” shows $P$ value of less than 0.05 ; “**” shows $P$ 
1 value of less than 0.01 ; “***” shows $P$ value of less than 0.001 . GraphPad Prism version 5.02

2 (GraphPad Prism Software Inc., San Diego, CA, USA) was used for data analysis.

\section{Results}

\section{1. HPSE1 aggravates endothelial LPS responses}

6 We first treated cells with purified catalytically active HPSE1 and then stimulated the cells

7 with LPS. Immunocytochemical staining using monoclonal 10E4 antibody confirmed

8 removal of heparan sulfate structures by HPSE1 (Fig. 1A, B). Cells treated with HPSE1

9 demonstrated morphological changes similar to the changes induced by LPS, namely

10 cytoskeletal rearrangement and disruption of cell-cell contacts (Fig. 1C, D). When HPSE1-

11 treated endothelial cells were stimulated with LPS, expression of IL-6 was significantly

12 higher than in untreated cells (Fig. 1E). IL-6 was selected as a readout of the LPS-induced

13 TLR4 response because IL-6 expression in endothelial cells was shown to be TLR4-

14 dependent ${ }^{36}$. In our experiments, the LPS-dependent expression of IL- 6 was abrogated by the

15 TLR4 inhibitor Cli-095 (data not shown). In a similar fashion, conditioned medium of the

16 HPSE1-overexpressing endothelial cells that secrete the protein to the cell culture supernatant

17 also promoted the LPS response in comparison to conditioned medium of the cells infected

18 with control virus (Fig. 1F). This data showed that catalytic activity of HPSE1 promotes the

19 LPS response in endothelial cells.

20 Endothelial cells can serve as a source of HPSE1 ${ }^{26}$. HPSE1 is expressed in the form of $65 \mathrm{kD}$

21 inactive precursor that is processed to an active $50 \mathrm{kD}$ isoform through cleavage by Cathepsin

$22 \mathrm{~L}(\mathrm{Ctsl})^{6}$. To assess whether or not endogenous HPSE1 is activated by LPS in endothelial

23 cells, we analyzed the expression of both HPSE1 isoforms in the conditioned medium of cells 
1 and cell lysates using antibody that recognizes both forms. We found $65 \mathrm{kD}$ inactive HPSE1

2 mainly in cell conditioned medium, whereas active $50 \mathrm{kD}$ form was mostly associated with

3 the cells. Furthermore, the content of the endogenous catalytically active $50 \mathrm{kD}$ HPSE1 was

4 time dependently increased after the LPS treatment (Fig. 1G-E) whereas the content of $65 \mathrm{kD}$

5 isoform in the conditioned medium was decreasing. These data point that endogenous HPSE1

6 can be activated after LPS treatment to provide for a positive TLR4-signaling feedback loop.

\section{2. HPSE2 overexpression protects from heparan sulfate-glycocalyx shedding}

8 To visualize the role of both heparanases in the turnover of the heparan sulfate glycocalyx in

9 the endothelial cells, we established overexpression of HPSE2 through lentiviral transduction

10 (Suppl. Fig. S1A-C). Similar to the endogenous HPSE2, overexpressed protein was released

11 from the cells and distributed between free soluble form in the conditioned medium and cell-

12 surface bound form (Suppl. Fig. S1B, C). HPSE-2 overexpressing endothelial cells showed

13 no signs of toxicity. Instead, proliferation rate was slightly increased and the cells were

14 protected against the TGF $\beta$-induced apoptosis (Suppl. Fig. S1D, E).

15 We next inspected HPSE2-overexpressing endothelial cells that were incubated in the

16 Polydimethylsiloxan (PDMS) - microfluidic chips under medium flow conditions. The chips

17 consisted of 4 parallel $10 \mathrm{~mm}$-long and $2 \mathrm{~mm}$-wide channels (Fig. 2A). The cells were

18 incubated under permanent medium flow conditions for 3 days. Endothelial cells developed a

19 more 3D heparan sulfate-enriched glycocalyx layer when were subjected to the medium flow

20 (Fig. 2B). Orthogonal views of the 3D z-scans confirmed extracellular localization of the

21 glycocalyx layer above the layer of cell nuclei (Fig. 2B). We then added catalytically active

22 HPSE1 to the medium used for chips perfusion. Under flow conditions this treatment also led

23 to the shedding of heparan sulfate layer from the cell surface (Fig. 2C, D). Remarkably, cells

24 overexpressing HPSE2 were protected against glycocalyx shedding by the exogenous HPSE1 
1 (Fig. 2C, D). Similar results were obtained when shear stress was increased up to 38.75

$2 \mathrm{dyn} / \mathrm{cm}^{2}$ (Supp. Fig. S2A).

3 Confirming inhibitory role of heparan sulfate on the TLR4 response, the cells cultured under

4 flow conditions demonstrated strongly diminished response to LPS (Fig. 2E). The expression

5 of HPSE1 in endothelial cells cultured under flow was also diminished (Suppl. Fig. S2B).

6 To assess whether or not HPSE2 prevents also the activity of endogenous HPSE1, lentivirus-

7 infected cells were stimulated with LPS and activation of HPSE1 was followed by the

8 accumulation of the active $50 \mathrm{kD}$ HPSE1 isoform (Fig. 2F, Suppl. Fig. S1F). The

9 overexpression of HPSE2 not only prevented the activity of exogenous HPSE1, but also LPS-

10 dependent increase of endogenous HPSE1 activity. This data confirmed antagonistic

11 relationship between the heparanases in endothelial cells. Accordingly, both expression and

12 activity of Ctsl in the HPSE2 overexpressing cells were slightly decreased (Supp. Fig. S2B,

$13 \mathrm{C})$.

\section{3. HPSE2 protects endothelial cells}

15 We next studied whether or not HPSE2 can also exert protective functions under pathological

16 situations. Control and HPSE2-overexpressing endothelial cells cultured under static

17 conditions were treated with different concentrations of LPS. Significant downregulation of

18 the LPS-induced IL-6 expression was observed in the HPSE2-overexpressing endothelial

19 cells at different LPS concentrations (Fig. 3A). To precisely characterize the LPS response in

20 HPSE2 overexpressing cells, Human Common Cytokine RT ${ }^{2}$ Profiler Array was performed.

21 Expressions of several pro-inflammatory cytokines, in particular, IL-6, IFNB1, IFNA1, CSF3

22 (G-CSF), and TNFSF10 were significantly downregulated in HPSE2-overexpressing cells

23 (Suppl. Fig. S3A). The data of the array were verified in independent RT-PCR experiment 
1 (Suppl. Fig. S3B-E). Further cytokines including CSF2, IL-1A, IL-1B, TGFB3, TNFRSF11

2 were downregulated to a lesser degree. Together, these data demonstrated general anti-

3 inflammatory effects of the HPSE2 overexpression in the endothelial cells. The

4 overexpression of HPSE2 have not induced any inflammatory effect on endothelial cells.

5 We then assessed morphological changes in the endothelial cells treated with LPS. Similar to

6 data reported by Zheng et al. ${ }^{37}$, we observed that control cells treated with $100 \mathrm{ng} / \mathrm{ml}$ LPS lost

7 cell-cell contacts and demonstrated decreased VE-Cadherin protein expression (Fig. 3B, C),

8 while HPSE2-overexpressing cells were protected and preserved cell-cell contacts much

9 better than control cells. These cells also demonstrated increased VE-Cadherin expression

10 after the LPS treatment (Fig. 3D). LPS-induced protein phosphorylation and activation of

$11 \mathrm{NF \kappa B}$ were less activated in HPSE-2 overexpressing endothelial cells as determined by

12 western blotting (Fig. 3E, F) and luciferase assay (Suppl. Fig. S2E). Together, these data

13 demonstrated a strong protection of endothelial cells exposed to LPS by HPSE2.

\section{4. HPSE2 prevents HPSE1 activity}

15 To test this idea, we made use of OGT 2115, an inhibitor of HPSE1 catalytic activity. The

16 compound decreased NFKB activation as shown in promoter activity luciferase assay (Suppl.

17 Fig. S2E). LPS-dependent expression and secretion of IL-6 was accordingly downregulated

18 in the presence of HPSE1 inhibitor (Fig. 4A, B). However, there was no additive effect after

19 HPSE1 inhibition in HPSE2 overexpressing cells (Fig. 4A, B; Suppl. Fig. S2E). This finding

20 suggested that both proteins are parts of the same molecular pathway and anti-inflammatory

21 role of HPSE2 is most likely mediated by its antagonistic action on HPSE1. A specific

22 protective role of HPSE2 was further confirmed using the $1 \mathrm{c} 7$ antibody to HPSE2 ${ }^{23}$ that can

23 block HPSE2 interaction with heparan sulfate ${ }^{38}$. Application of the $1 \mathrm{c} 7$ antibody and thus

24 displacement of the protein from cell surface heparan sulfate glycocalyx structures resulted in 
1 abrogation of HPSE2 protective action and strong activation of LPS response (Fig. 4C). We

2 suggest that HPSE1regulates TLR4 response in endothelial cells. The effects are counteracted

3 by HPSE2 bound to cell surface heparan sulfate.

\section{5. HPSE2 inhibits LPS binding to TLR4 receptor complex}

5 We next studied the mechanisms of the regulation of LPS response in endothelial cells by

6 HPSE1. Molecular mechanisms of TLR4 signaling are extensively investigated. The LPS

7 molecule is first bound to TLR4 co-receptor, CD14 ${ }^{39}$. Thereafter, LPS is transferred to the

8 complex of TLR4 with an accessory molecule, Lymphocyte antigen 96, (also known as

$9 \mathrm{MD} 2)$ to induce the activation of intracellular adapters and subsequent protein

10 phosphorylation cascades ${ }^{40}$. Several mechanisms could account for the role of HPSE1. First,

11 TLR4 can be further activated by heparan sulfate fragments originating from the HPSE1

12 catalytic activity ${ }^{16}$. Second, LPS ligand binding to the CD14 receptor could be affected by

13 heparan sulfate. Finally, the interaction of TLR4 with co-receptors on the cell membrane can

14 be regulated by heparan sulfate. We first tested whether accumulation of heparan sulfate

15 fragments during the cells stimulation with LPS can lead to further activation of TLR4.

16 Exogenous heparan sulfate caused a weak increase in IL-6 expression, even at high

17 concentrations (Fig. 5A). This response was also decreased in HPSE2-overexpressing cells

18 (Fig. 5A). To investigate whether or not endogenously produced soluble heparan sulfate

19 fragments can promote TLR4 activation, conditioned medium of cells treated with LPS for 3

$20 \mathrm{~h}$, was used for stimulation of naïve cells. We found that supernatant of LPS-treated cells

21 caused strong increase of IL-6 expression (Fig. 5B). Proteinase $\mathrm{K}$ is a serine protease used to

22 digest proteins in biological samples. Removal of protein components from the supernatant

23 by incubation with beads-immobilized proteinase K prevented expression of IL-6. Removal

24 of remaining LPS using Endotoxin-Removal beads caused complete abrogation of IL-6 
1 expression (Fig. 5B). Exogenous heparan sulfate at concentration of $100 \mathrm{ng} / \mathrm{ml}$ strongly

2 potentiated endothelial cell response to LPS (Fig. 5C). This response was documented by the

3 3-folds increase of the LPS-induced IL-6 expression in the presence of exogenous heparan

4 sulfate. These findings suggested that concentration of endogenous heparan sulfate fragments

5 produced during $3 \mathrm{hrs}$ of LPS stimulation was not sufficient to potentiate activation of TLR4.

6 However, in the case of significant accumulation, soluble heparan sulfate fragments can

7 potentiate inflammatory response of endothelial cells to LPS.

8 We then investigated whether HPSE2 can affect LPS binding using biotin-LPS. Cells were

9 incubated on ice to prevent internalization of receptors. Cell binding of biotin-LPS was not

10 decreased by overexpression of HPSE2 (Fig. 5D), suggesting that LPS binding to CD14 was

11 not affected. The specificity of biotin-LPS binding to CD14 was confirmed by application of

12 CD14 blocking antibody. Over 70\% of the Biotin-LPS binding was blocked by CD14

13 antibody but not isotypic IgG.

14 TLR4 intracellular signaling is mediated by the recruitment of two adapter proteins, MyD88

15 and TIR-domain-containing adapter-inducing interferon- $\beta$ (TRIF) ${ }^{41}$. We observed diminished

16 LPS-induced expression of IL-6 suggesting impaired MyD88-pathway activation in HPSE2-

17 overexpressing cells. We further investigated the expression of IFNB1 and chemokine ligand-

185 (CCL5), also known as RANTES that is mediated by TRIF adapter pathway activation (Fig.

19 6A). Our data show that both, MyD88 and TRIF-mediated signaling pathways of TLR4 are

20 inhibited by HPSE2. Since LPS binding was not impaired by the overexpression of HPSE2,

21 we reasoned that HPSE2 most likely interfered with the LPS transfer from CD14 to

22 TLR4/MD2 complex. In order to verify this hypothesis, a pull-down assay using biotin-LPS

23 and streptavidin magnetic beads was performed. Cells were incubated for $1 \mathrm{~h}$ on ice in the

24 presence of $50 \mathrm{ng} / \mathrm{ml}$ biotin-LPS to allow its binding to the cell surface. Then, the cells were 
1 transferred to $37^{\circ} \mathrm{C}$ for the indicated time to enable further signaling events to take place.

2 The results supported our hypothesis (Fig. 6B, C) as less TLR4 was detected in the biotin-

3 LPS complexes from HPSE2-overexpressing endothelial cells. Regulation of CD14/TLR4

4 association by HPSE1 and protective role of HPSE2 was confirmed by the Duolink proximity

5 ligation assay - a method to detect protein-protein interaction (Fig. 6D, E). To investigate the

6 endocytosis of TLR4, cell surface staining on living cells was performed. To stop endocytosis

7 and prevent staining of intracellular TLR4, cells were placed on ice after LPS stimulation and

8 stained with anti-TLR4 antibody (Fig. 6F, G). Decreased staining suggested active

9 endocytosis of the receptor complex in control cells. However, in HPSE2-overexpressing

10 cells TLR4 remained on the cell surface. These findings imply that membrane-bound heparan

11 sulfate prevents LPS transfer from CD14 to TLR4/MD2 complex and its removal by HPSE1

12 promotes the LPS response of endothelial cells.

\section{6. HPSE2 is protective in vivo}

14 To investigate how expression of endogenous HPSE2 is regulated during sepsis, we used the

15 mouse CLP polymicrobial sepsis model. We observed decreased HPSE2 expression in serum

16 of CLP mice (Fig. 7A, B). In the kidney we observed HPSE2 expression in medullary

17 capillaries. This expression of HPSE2 was strongly downregulated in sepsis (Fig. 7C, D).

18 Negative control staining is shown in supplementary Fig. S3F.

19 We next purified HPSE2 from conditioned medium of HEK293T cells transduced with LV-

20 HPSE2 overexpression virus. Application of the exogenous HPSE2 diminished LPS response

21 of the endothelial cells in vitro in a similar fashion to HPSE2 overexpression (Supplementary

22 Fig. S3G). When co-injected intravenously along with LPS in mice, HPSE2 had similar

23 protective effects and caused statistically significant decrease in the plasma content of TNF $\alpha$ 
1 and IL-6 $2 \mathrm{~h}$ after injection (Fig. 7E, F). This data suggest that HPSE2 has also an endothelial

2 protective function in microvasculature in vivo and can have some therapeutic potential.

\section{Discussion}

4 We demonstrated an important protective role for HPSE2 both in vivo and in vitro. Using

5 different approaches we showed that HPSE1 activity aggravates endothelial response to LPS,

6 whereas HPSE2 prevents activation of HPSE1, heparan sulfate shedding, and inflammatory

7 responses mediated by TLR4. Our findings support an essential role for an intact glycocalyx

8 in the endothelium. Glycocalyceal shedding occurs in many diseases and pathological insults.

9 However, the mechanisms how glycocalyceal turnover is regulated and what the

10 consequences are when the process is perturbed is still imperfectly understood. A high

11 expression of HPSE1, the sole enzyme capable of cleaving heparan sulfate, is damaging for

12 the endothelium ${ }^{42}$. Although the role of HPSE2 as an antagonist of HPSE1 is well appreciated

13 in cancer, how the interaction of these proteins can affect endothelial cells is less clear.

14 The role of heparan sulfate in the TLR4-mediated LPS response is not well understood.

15 Soluble heparan sulfate fragments generated by HPSE1 can serve as ligand for TLR $4{ }^{16}$.

16 Treatment of macrophages with HPSE1 facilitated an inflammatory response. On the

17 contrary, in microglia heparan sulfate promoted TLR4/CD14 complex formation and HPSE1

18 transgenic cells showed less inflammatory response to LPS ${ }^{20}$. Our data suggest that heparan

19 sulfate prevents the activation of TLR4 signaling and inflammatory response of endothelium.

20 HPSE1 is an important component of the TLR4 signalosome as heparan sulfate cleavage

21 facilitates cellular response and promotes inflammatory reaction of the endothelial cells.

22 Both heparanases are present in human plasma. HPSE1 upregulation is associated with many

23 disease states. Our data showed decreased plasma HPSE2 expression in mouse sepsis models 
1 indicating that cross-talk of the heparanases is important in vivo. Our data suggest that

2 endothelial cell express and release HPSE1 and HPSE2 for local regulation of heparan sulfate

3 turnover. Our mechanistic studies showed that HPSE2 bound to heparan sulfate on the

4 endothelial cell surface prevents activation of HPSE1 and heparan sulfate shedding. We

5 found that HPSE2 displacement from the cell surface by the $1 \mathrm{c} 7$ antibody ${ }^{38}$ led to the

6 abrogation of HPSE2 protective function. Taking into account poor development of the

7 heparan sulfate glycocalyx under normal static cell culture conditions we applied

8 microfluidic chip model to demonstrate the protective role of HPSE2 ${ }^{43,44}$. In the microfluidic

9 experiments, HPSE2 overexpressing cells were strongly protected from heparan sulfate loss

10 by HPSE1. This observation further confirmed that HPSE2 expressed by endothelial cells

11 partially remained bound to the heparan sulfate glycocalyx and counteracted its cleavage by

12 HPSE1. Inhibiting role of the glycocalyx in TLR4 receptor signaling was confirmed by

13 diminished LPS response of the cells incubated under flow conditions.

14 In macrophages HPSE1 itself was shown to induce TLR dependent signaling ${ }^{21}$. In endothelial 15 cells HPSE1 induced rather weak inflammatory response by itself and only by the prolonged

16 incubation (data not shown). Thus, in the context of TLR4 activation on the endothelium,

17 remodeling of the glycocalyx on the cell surface seems more important. Interestingly,

18 exogenous heparan sulfate strongly potentiated cell response to LPS. The finding can

19 probably be explained by competitive binding of HPSE2 to soluble heparan sulfate resulting

20 in its' removal from the cell membrane-associated glycocalyx.

21 We used biotin-LPS to demonstrate that HPSE2 does not interfere with LPS binding to the

22 CD14 but rather prevents LPS transfer to TLR4 and activation of the cellular signaling. As a

23 result, the inflammatory response was reduced. Early reports suggested that endothelial cells

24 express only the soluble form of CD14 $4^{45,46}$. On the contrary, more recent reports showed the 
1 expression and the role for membrane CD14 in endothelial response to LPS ${ }^{47,48}$. Lloyd-Jones

2 et al. showed that membrane-bound CD14 is indispensable for the activation of TRIF-

3 mediated pathway in endothelial cells ${ }^{48}$. We showed that both, MyD88- and TRIF-dependent

4 pathways are affected by HPSE2. Therefore, we assume that membrane bound form of CD14

5 is regulated by heparan sulfate. However, involvement of soluble CD14 can not be excluded.

6 In vivo co-injection of HPSE2 along with LPS in mice led to decreased cytokines expression

7 in plasma. In polymicrobial CLP mouse sepsis model the expression of HPSE2 in renal

8 medullary capillaries was decreased. Thus, loss of HPSE2 can promote microcirculatory

9 disorder in sepsis leading to organ failure.

10 Our results suggest that HPSE2, expressed locally by the endothelial cells or delivered with

11 blood, fulfills protective role in microvasculature via protection from heparan sulfate

12 shedding and anti-inflammatory regulation of TLR4 signaling. HPSE2 is a novel molecule

13 which exerts a direct protective effect on the endothelial glycocalyx thereby maintaining

14 microvascular function and stability as well as protecting the endothelium from damage. Our

15 results in vivo suggest that HPSE2 supplementation may be beneficial for the protection of

16 the microvasculature. This novel mechanism supports therapeutic strategies to stabilize the

17 endothelial glycocalyx.

\section{Acknowledgments}

19 a) We are grateful to Prof. Israel Vlodavsky (Technion, Haifa, Israel) for giving us 1c7

20 antibody to HPSE2.

21 b) Sources of funding: Grants from German Federal Ministry of Education and Research

22 (BMBF) Nr. 031A577A and 031A577B funded this research. This work was also supported

23 by a grant for the German Research Council to H.H. Ha 1388/17-1. 
2 c) Disclosures: none.

\section{References}

6 1. Weinbaum S, Tarbell JM, Damiano ER. The Structure and Function of the Endothelial

7 Glycocalyx Layer. Annual Review of Biomedical Engineering. 2007;9(1):121-167.

8 2. Schmidt EP, Yang Y, Janssen WJ, Gandjeva A, Perez MJ, Barthel L, Zemans RL, 9 Bowman JC, Koyanagi DE, Yunt ZX, Smith LP, Cheng SS, Overdier KH, Thompson $\mathrm{KR}$, Geraci MW, et al. The pulmonary endothelial glycocalyx regulates neutrophil adhesion and lung injury during experimental sepsis. Nature Medicine. 2012;18(8):1217-1223.

3. Florian JA. Heparan Sulfate Proteoglycan Is a Mechanosensor on Endothelial Cells. Circulation Research. 2003;93(10):136e - 142.

4. Ori A, Wilkinson MC, Fernig DG. A systems biology approach for the investigation of the heparin/heparan sulfate interactome. Journal of Biological Chemistry. 2011;286(22):19892-19904.

5. Ushiyama A, Kataoka H, Iijima T. Glycocalyx and its involvement in clinical pathophysiologies. Journal of Intensive Care. 2016;4(1):1-11.

6. Rabelink TJ, de Zeeuw D. The glycocalyx — linking albuminuria with renal and cardiovascular disease. Nature Reviews Nephrology. 2015;11(11):667-676.

7. Kim YH, Nijst P, Kiefer K, Tang WHW. Endothelial Glycocalyx as Biomarker for Cardiovascular Diseases: Mechanistic and Clinical Implications. Current Heart Failure Reports. 2017;14(2):117-126.

8. Song JW, Zullo J, Lipphardt M, Dragovich M, Zhang FX, Fu B, Goligorsky MS. Endothelial glycocalyx-the battleground for complications of sepsis and kidney injury. Nephrology Dialysis Transplantation. 2018;33(2):203-211.

28 9. Chelazzi C, Villa G, Mancinelli P, De Gaudio AR, Adembri C. Glycocalyx and sepsisinduced alterations in vascular permeability. Critical Care. 2015;19(1):1-7.

30 10. Martin L, Koczera P, Zechendorf E, Schuerholz T. The Endothelial Glycocalyx: New Diagnostic and Therapeutic Approaches in Sepsis. BioMed Research International. 2016;2016. 
1 11. Lin X, Wei G, Shi Z, Dryer L, Esko JD, Wells DE, Matzuk MM. Disruption of gastrulation and heparan sulfate biosynthesis in EXT1-deficient mice. Developmental Biology. 2000;224(2):299-311.

4 12. Stickens D. Mice deficient in Ext2 lack heparan sulfate and develop exostoses. Development. 2005;132(22):5055-5068.

6 13. Melo CM, Origassa CST, Theodoro TR, Matos LL, Miranda TA, Accardo CM,

14. Shafat I, Ilan N, Zoabi S, Vlodavsky I, Nakhoul F. Heparanase levels are elevated in the urine and plasma of type 2 diabetes patients and associate with blood glucose levels. PLoS ONE. 2011;6(2).

15. Vijay K. Toll-like receptors in immunity and inflammatory diseases: Past, present, and future. International Immunopharmacology. 2018;59(February):391-412.

16. Goodall KJ, Poon IKH, Phipps S, Hulett MD. Soluble heparan sulfate fragments generated by heparanase trigger the release of pro-inflammatory cytokines through TLR-4. PLoS ONE. 2014;9(10).

17. Akbarshahi H, Axelsson JBF, Said K, Malmström A, Fischer H, Andersson R. TLR4 dependent heparan sulphate-induced pancreatic inflammatory response is IRF3mediated. Journal of Translational Medicine. 2011;9(1):1-8.

18. Lerner I, Hermano E, Zcharia E, Rodkin D, Bulvik R, Doviner V, Rubinstein AM, Ishai-Michaeli R, Atzmon R, Sherman Y, Meirovitz A, Peretz T, Vlodavsky I, Elkin M. Heparanase powers a chronic inflammatory circuit that promotes colitis-associated

19. Brunn GJ, Bungum MK, Johnson GB, Platt JL. Conditional signaling by Toll-like

20. O'Callaghan P, Li JP, Lannfelt L, Lindahl U, Zhang X. Microglial heparan sulfate proteoglycans facilitate the cluster-of-differentiation 14 (CD14)(WARNING)Toll-like receptor 4 (TLR4)-dependent inflammatory response. Journal of Biological Chemistry. 2015;290(24):14904-14914.

21. Blich M, Golan A, Arvatz G, Sebbag A, Shafat I, Sabo E, Cohen-Kaplan V, Petcherski S, Avniel-Polak S, Eitan A, Hammerman H, Aronson D, Axelman E, Ilan N, 
1 22. McKenzie E, Tyson K, Stamps A, Smith P, Turner P, Barry R, Hircock M, Patel S, Barry E, Stubberfield C, Terrett J, Page M. Cloning and expression profiling of Hpa2, a novel mammalian heparanase family member. Biochemical and Biophysical Research Communications. 2000;276(3):1170-1177.

23. Levy-Adam F, Feld S, Cohen-Kaplan V, Shteingauz A, Gross M, Arvatz G, Naroditsky I, Ilan N, Doweck I, Vlodavsky I. Heparanase 2 interacts with heparan sulfate with high affinity and inhibits heparanase activity. Journal of Biological Chemistry. 2010;285(36):28010-28019.

24. Vlodavsky I, Gross-cohen M, Weissmann M, Ilan N, Ralph D. Opposing functions of heparanase-1 and heparanase-2 in cancer progression. Trends Biochem Sci. 2018;43(1):18-31.

25. Chen G, Wang D, Vikramadithyan R, Yagyu H, Saxena U, Pillarisetti S, Goldberg IJ. Inflammatory Cytokines and Fatty Acids Regulate Endothelial Cell Heparanase Expression. Biochemistry. 2004;43(17):4971-4977.

26. Godder K, Vlodavsky I, Eldor A, Weksler BB, Haimovitz-Freidman A, Fuks Z. Heparanase activity in cultured endothelial cells. Journal of Cellular Physiology. 1991;148(2):274-280.

27. Edovitsky E, Lerner I, Zcharia E, Peretz T, Vlodavsky I, Elkin M. Role of endothelial heparanase in delayed-type hypersensitivity. Blood. 2006;107(9):3609-3616.

28. Hodjat M, Haller H, Dumler I, Kiyan Y. Urokinase receptor mediates doxorubicininduced vascular smooth muscle cell senescence via proteasomal degradation of TRF2. Journal of Vascular Research. 2013;50(2).

29. Zufferey R, Nagy D, Mandel RJ, Naldini L, Trono D. Multiply attenuated lentiviral vector achieves efficient gene delivery in vivo. Nature Biotechnology. 1997;15(9):871-875.

30. Naldini L, Blomer U, Gallay P, Ory D, Mulligan R, Gage FH, Verma IM, Trono D. In Vivo Gene Delivery and Stable Transduction of Nondividing Cells by a Lentiviral Vector. Science. 1996;272(5259):263-267.

31. Farsari M, Chichkov BN. Materials processing: Two-photon fabrication. Nature Photonics. 2009;3(8):450-452.

32. Duffy DC, McDonald JC, Schueller OJA, Whitesides GM. Rapid prototyping of microfluidic systems in poly(dimethylsiloxane). Analytical Chemistry. 1998;70(23):4974-4984.

33. Schappe MS, Desai BN. Measurement of TLR4 and CD14 Receptor Endocytosis Using Flow Cytometry. Bio-protocol. 2018;8(14):e2926. 
1 34. Kiyan J, Kiyan R, Haller H, Dumler I. Urokinase-induced signaling in human vascular smooth muscle cells is mediated by PDGFR- $\beta$. EMBO Journal. 2005;24(10).

35. Menne J, Shushakova N, Bartels J, Kiyan Y, Laudeley R, Haller H, Park J-K, Meier M. Dual inhibition of classical protein kinase $C-\alpha$ and protein kinase $C-\beta$ isoforms protects against experimental murine diabetic nephropathy. Diabetes. 2013;62(4).

36. Anjum SA, Lawrence H, Holland JP, Kirby JA, Deehan DJ, Tyson-Capper AJ. Effect of cobalt-mediated Toll-like receptor 4 activation on inflammatory responses in endothelial cells. Oncotarget. 2016;7(47):1-8.

37. Zheng X, Zhang W, Hu X. Different concentrations of lipopolysaccharide regulate barrier function through the PI3K/Akt signalling pathway in human pulmonary microvascular endothelial cells. Scientific Reports. 2018;8(1):1-11.

38. Gross-Cohen M, Feld S, Doweck I, Neufeld G, Hasson P, Arvatz G, Barash U, Naroditsky I, Ilan N, Vlodavsky I. Heparanase 2 attenuates head and neck tumor vascularity and growth. Cancer Research. 2016;76(9):2791-2801.

39. Ryu JK, Kim SJ, Rah SH, Kang JI, Jung HE, Lee D, Lee HK, Lee JO, Park BS, Yoon TY, Kim HM. Reconstruction of LPS Transfer Cascade Reveals Structural Determinants within LBP, CD14, and TLR4-MD2 for Efficient LPS Recognition and Transfer. Immunity. 2017;46(1):38-50.

40. O'Neill LAJ, Golenbock D, Bowie AG. The history of Toll-like receptors-redefining innate immunity. Nature Reviews Immunology. 2013;13(6):453-460.

41. Gay NJ, Symmons MF, Gangloff M, Bryant CE. Assembly and localization of Tolllike receptor signalling complexes. Nature Reviews Immunology. 2014;14(8):546-558.

42. Han J, Mandal AK, Hiebert LM. Endothelial cell injury by high glucose and heparanase is prevented by insulin, heparin and basic fibroblast growth factor. Cardiovascular Diabetology. 2005;4:1-12.

43. Potter DR, Damiano ER. The hydrodynamically relevant endothelial cell glycocalyx observed in vivo is absent in vitro. Circulation Research. 2008;102(7):770-776.

44. Tsvirkun D, Grichine A, Duperray A, Misbah C, Bureau L. Microvasculature on a chip: Study of the Endothelial Surface Layer and the flow structure of Red Blood Cells. Scientific Reports. 2017;7(October 2016):1-11.

45. Frey BE a, Miller DS, Jahr G, Sundan A, Espevik IIT, Finlay SBB, Wright SD. of British Columbia, Vancouver, British Columbia, Canada, V6T 1Z3; the *Laboratory of Cellular Physiology and Immunology, The Rockefeller University, New York, New York, 10021; the \$Institute for Cancer Research, 7005 Trondheiro, Norway; and the IIInstitu. Response. 1992;176(December). 
1 46. Haziot A, Rong GW, Silver J, Goyert SM. Recombinant soluble CD14 mediates the activation of endothelial cells by lipopolysaccharide. J Immunol. 1993;151(3):15001507.

4 47. Jersmann HPA, Hii CST, Hodge GL, Ferrante A. Synthesis and surface expression of CD14 by human endothelial cells. Infection and Immunity. 2001;69(1):479-485.

6 48. Lloyd-Jones KL, Kelly MM, Kubes P. Varying importance of soluble and membrane

7 CD14 in endothelial detection of lipopolysaccharide. Journal of immunology (Baltimore,

8 Md. : 1950). 2008;181(2):1446-53.

9 


\section{Highlights.}

$2>$ Catalytic activity of Heparanase 1 aggravates TLR4 signaling and endothelial

3 response to LPS

$4>$ Heparanase 2 diminishes endothelial response to LPS

$5>$ Heparanase 2 does not affect LPS binding to CD14 but inhibits LPS presentation to

6 TLR4

7

Expression of HPSE2 in vivo is decreased in sepsis. 
A

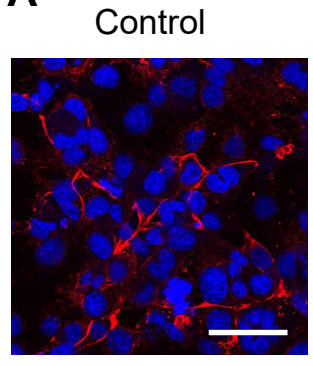

C

Control

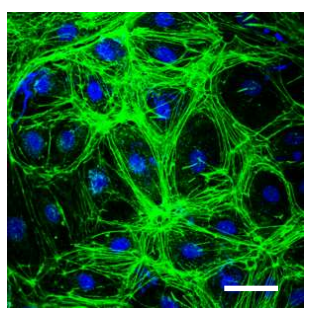

G

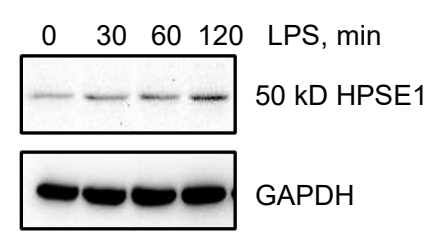

E

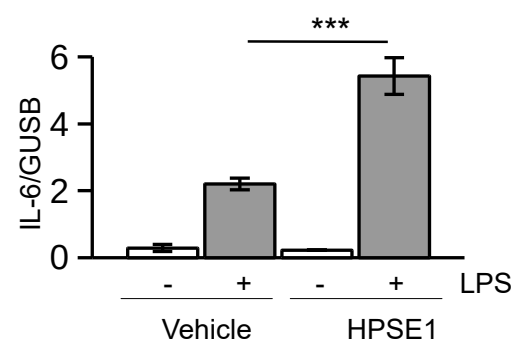

HPSE1

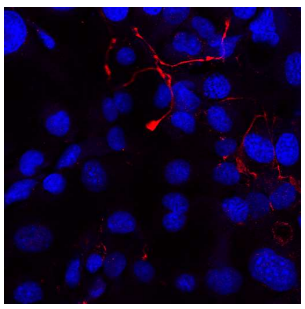

HPSE1

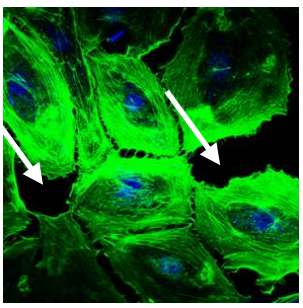

H

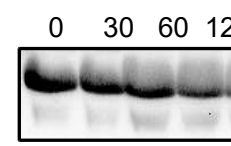

$65 \mathrm{kD}$ $50 \mathrm{kD}$ HPSE 1
LPS+HPSE1

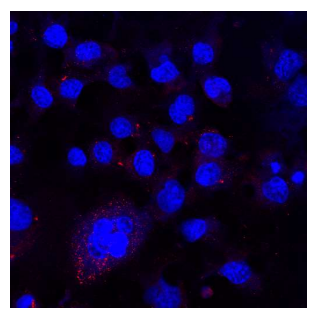

LPS+HPSE1

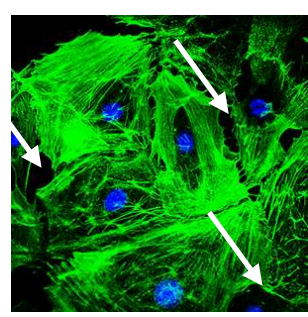

F

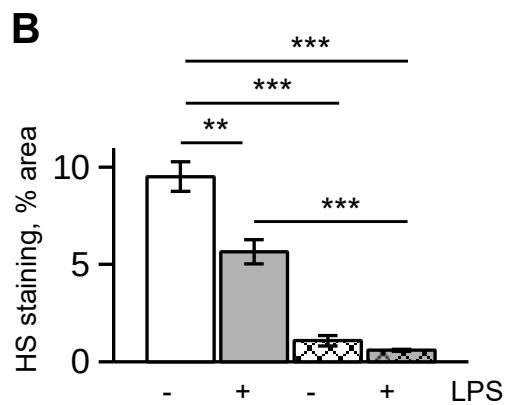

D

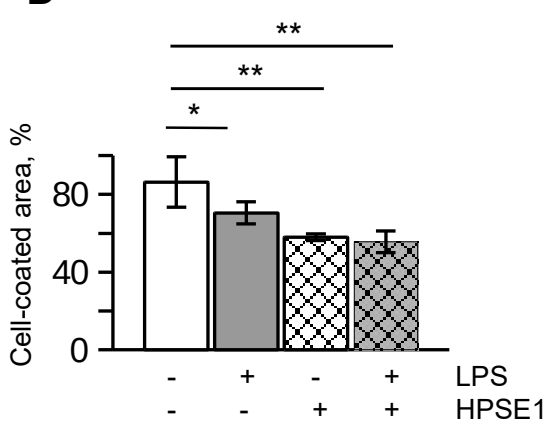

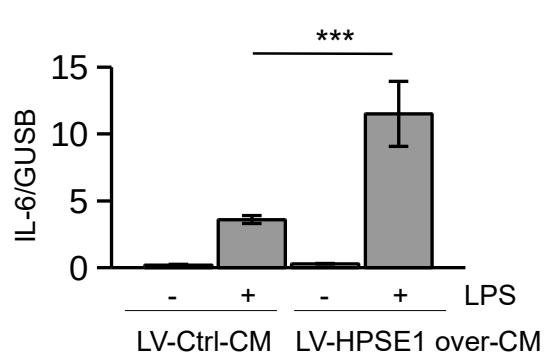

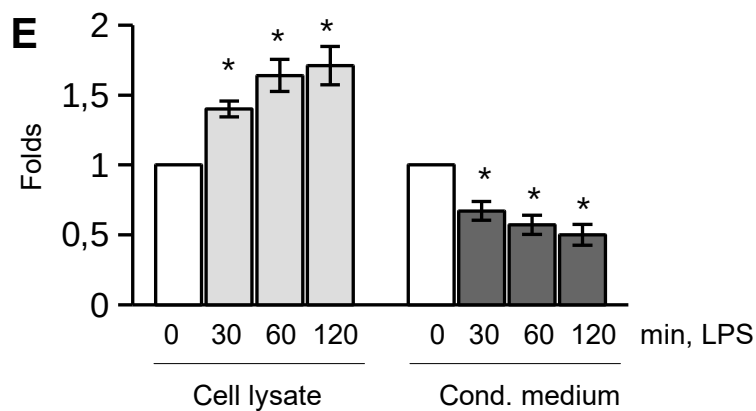

Figure 1. HPSE1 aggravates endothelial cell response to LPS. A. HMEC-1 cells were treated with active HPSE1 for $1 \mathrm{~h}$ prior to LPS stimulation. Then, cells were treated with $100 \mathrm{ng} / \mathrm{ml}$ LPS for $3 \mathrm{hrs}$. Cells were fixed and stained with 10A4 antibody for heparan sulfate (Alexa 594). Nuclei were stained with DAPI. Scale Bar $50 \mu \mathrm{m}$ B. Quantification of heparan sulfate stainings. Percentage of stained areas was calculated using ImageJ. C. Primary endothelial cells treated as in A were stained with Alexa 488-Phalloidin (green) and DAPI. White arrows show loss of cellular contacts. Scale Bar $50 \mu \mathrm{m}$. D. Quantification of phalloidin images. Percentage of cell-coated areas was calculated using ImageJ. E. HMEC-1 cells were treated with catalytically active HPSE1 and then stimulated with LPS. IL-6 expression was assessed by RT-PCR. F. Cell were treated with conditioned medium from control (LV-CtrlCM) and HPSE1 overexpression (LV-HPSE1 over-CM) lentivirus-transduced HMEC-1 cells for $1 \mathrm{~h}$ prior to LPS stimulation. IL-6 expression was assessed by RT-PCR. G. Expression of $50 \mathrm{kD}$ active HPSE1 after LPS stimulation of endothelial cells assessed in cell lysates by western blotting. H. Expression of $65 \mathrm{kD}$ and $50 \mathrm{kD}$ isoforms of HPSE1 was assessed in conditioned medium of LPS-stimulated endothelial cells. E. Quantification of three independent western blotting experiments as shown in $\mathrm{G}$ (Cell lysate) and $\mathrm{H}$ (Cond. Medium). Data were quantified using QuantityOne software (BioRad). 
A

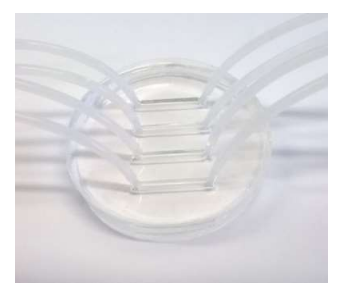

D

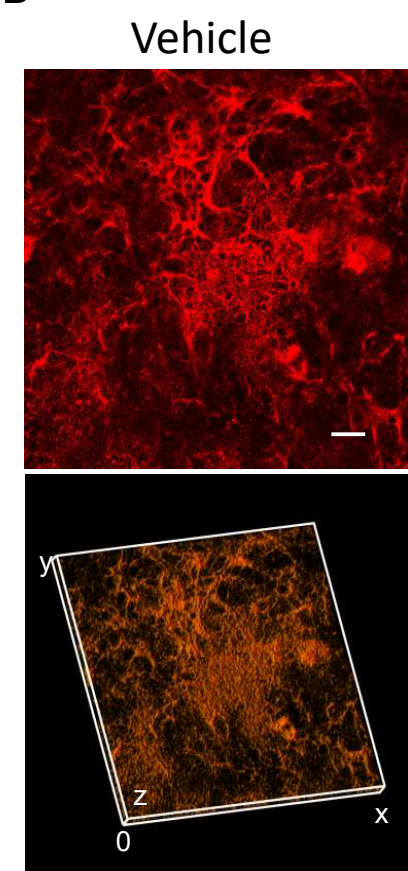

B

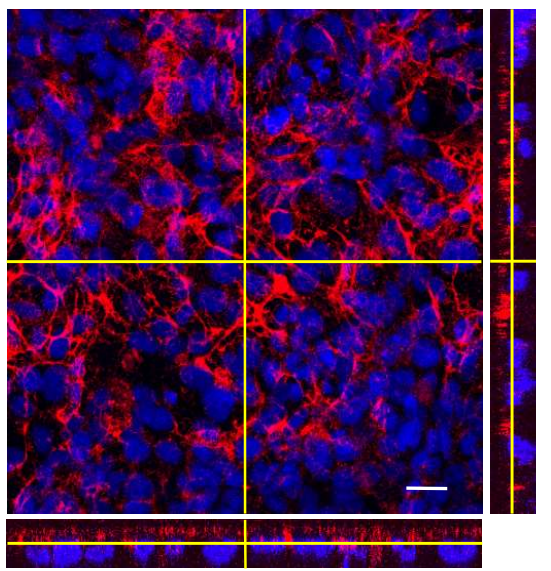

C

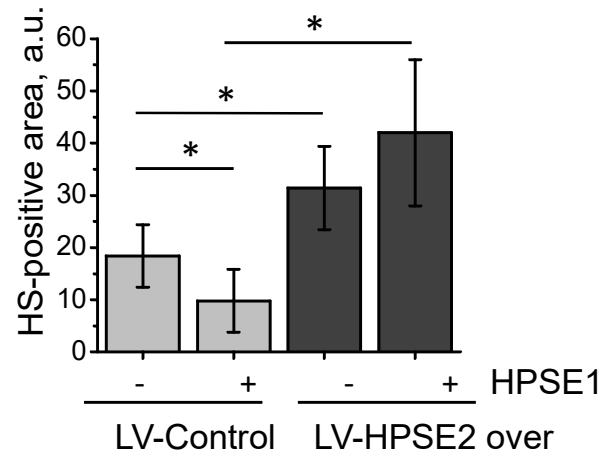

LV-HPSE2 over

L-Control

HPSE1

Vehicle

HPSE1
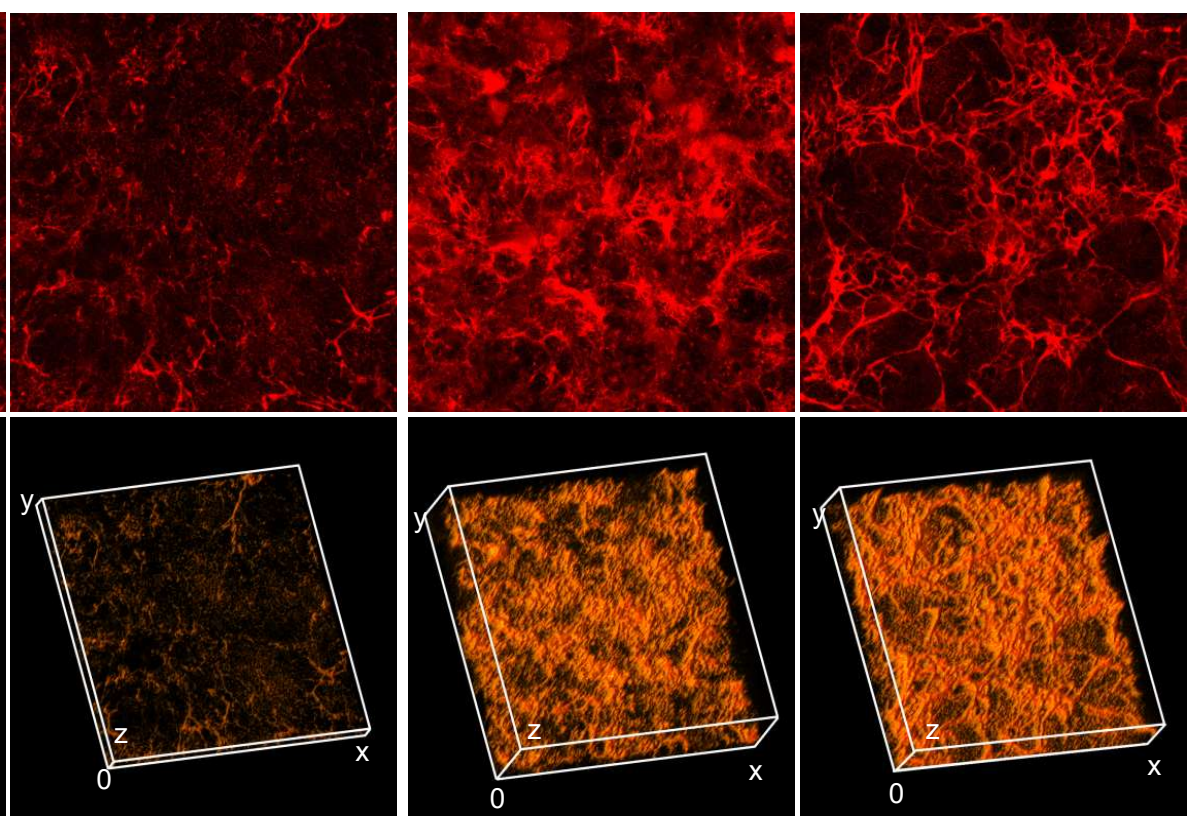

E
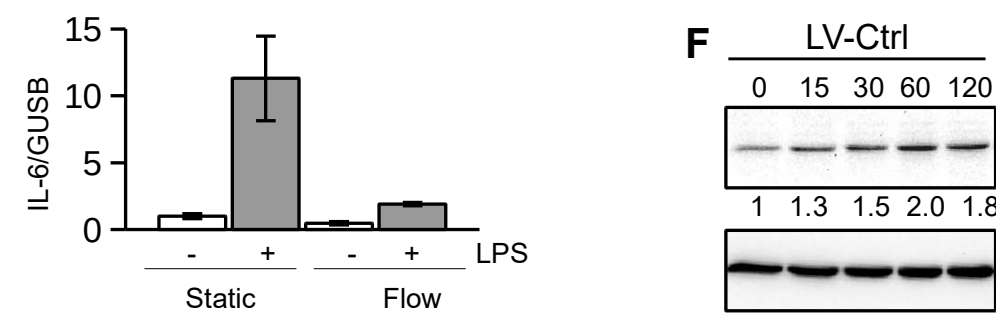

\begin{tabular}{ccc} 
LV-HPSE2-over \\
\hline $0 \quad 15 \quad 30 \quad 60 \quad 120$
\end{tabular}

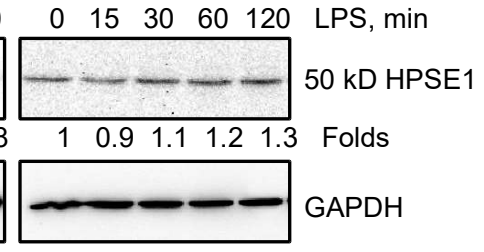

Figure 2. HPSE2 overexpression protects endothelial heparan sulfate glycocalyx in a microfluidic chip model. A. 4-channels PDMS-microfluidic chip. B. Development of 3D heparan sulfate glycocalyx layer after endothelial cells cultivation under flow conditions ( 3 days, $\left.0.1 \mathrm{dyn} / \mathrm{cm}^{2}\right)$ was assessed by $3 \mathrm{D}$ confocal microscopy using 10E4 antibody to heparan sulfate followed by image reconstruction using ImageJ software. DraQ5 was used as a nuclear stain. Yellow lines show position of orthogonal slices. Bottom and right panels show corresponding orthogonal slices of the sum images. C. Control and HPSE2 overexpression-lentivirus-infected endothelial cells were cultivated in the microfluidic chip for 3 days, and then perfused with recombinant HPSE1 for $4 \mathrm{hrs}$. Cells were fixed by perfusion with PFA as described in the methods section. Heparan sulfate content was quantified using ImageJ software after 3D confocal microscopy. Experiment was independently repeated in 4 chips. D. 3D reconstruction of heparan sulfate glycocalyx layer images of lentivirus-infected endothelial cells after incubation in the microfluidic chip and recombinant HPSE1 treatment. The 3D reconstruction was performed using ImageJ software. Scale bar $20 \mu \mathrm{m}$. E. Endothelial cells incubated in microfluidic chips under static and flow conditions were stimulated with $100 \mathrm{ng} / \mathrm{ml}$ LPS for $3 \mathrm{hrs}$. IL-6 expression was assessed by TaqMan RT-PCR. F. 50 kD HPSE1 expression in lysates of LPS-stimulated endothelial cells. 


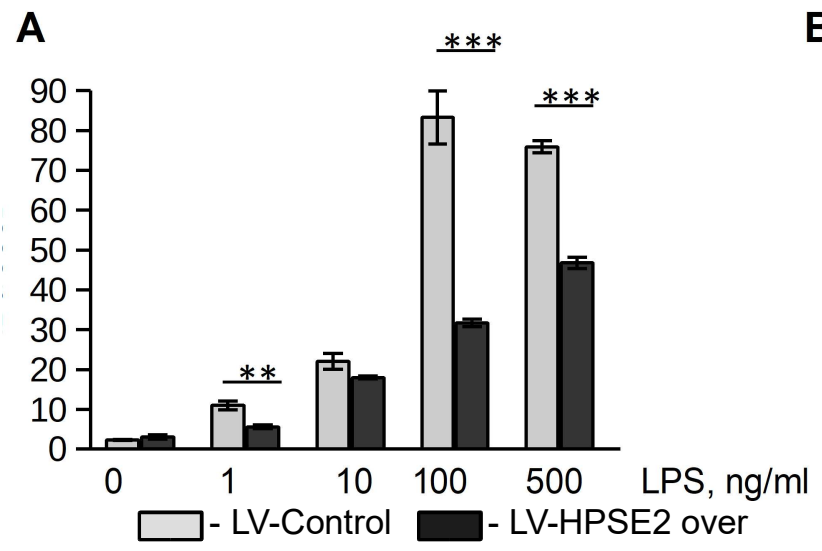

C

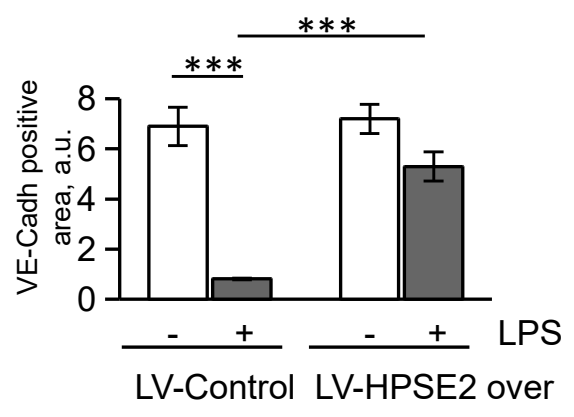

$\mathbf{E}$
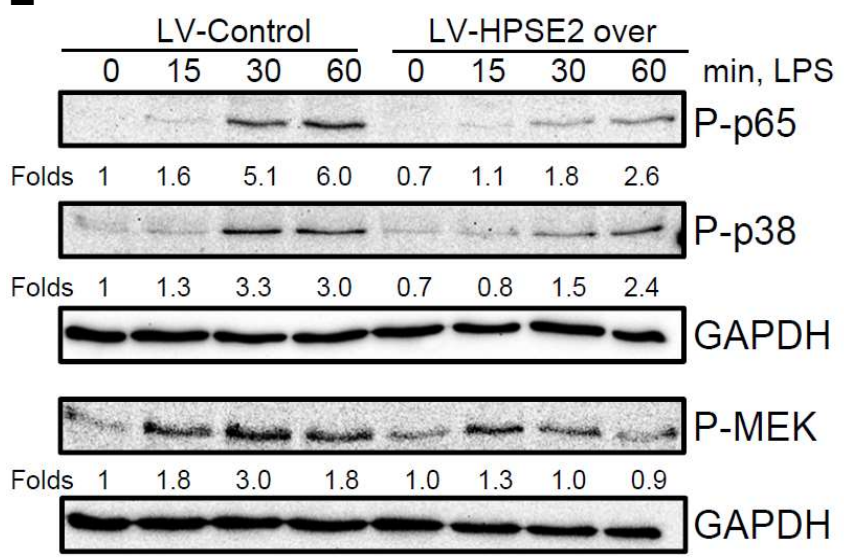

B

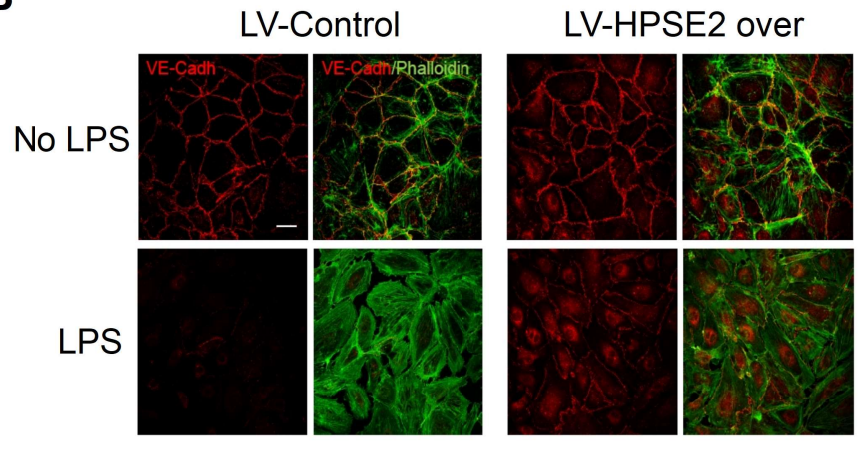

D

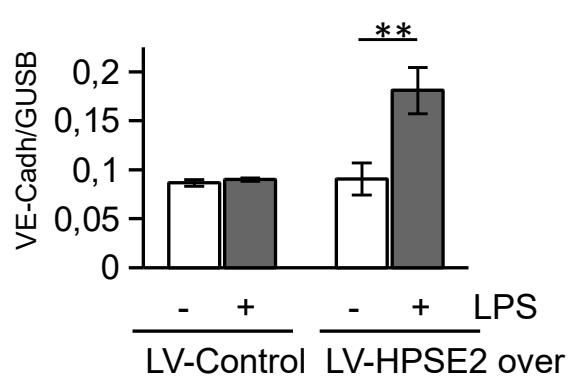

$\mathbf{F}$

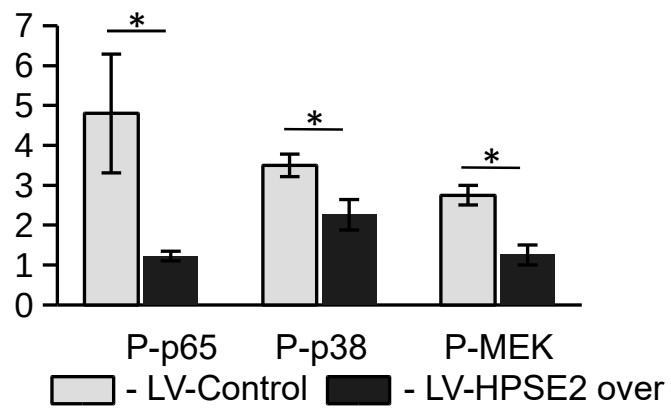

Figure 3. HPSE2 protects endothelial cells from LPS-induced damage. A. Endothelial cells infected with Control and HPSE2- overexpression lentivirus were treated with different concentrations of LPS for $3 \mathrm{hrs}$ as indicated. IL-6 expression was assessed by TaqMan RT-PCR. B. Primary endothelial cells treated with LPS for $24 \mathrm{hrs}$ cells were fixed and immunostained for VE-Cadherin (Alexa 594) and Phalloidin (Alexa 488). C. The percentage of VE-Cadherin positive areas was calculated using ImageJ. D. Expression of VE-Cadherin mRNA in LPS treated cells was quantified by TaqMan RT-PCR. E. Endothelial cells were stimulated with 1 $\mu \mathrm{g} / \mathrm{ml}$ LPS for indicated times. Protein phsophorylation was assessed by western blotting. F. Quantification of phosphorylation of p65, p38, p-MEK at $30 \mathrm{~min}$ of LPS stimulation quantified from three independent western blotting experiments. 
A

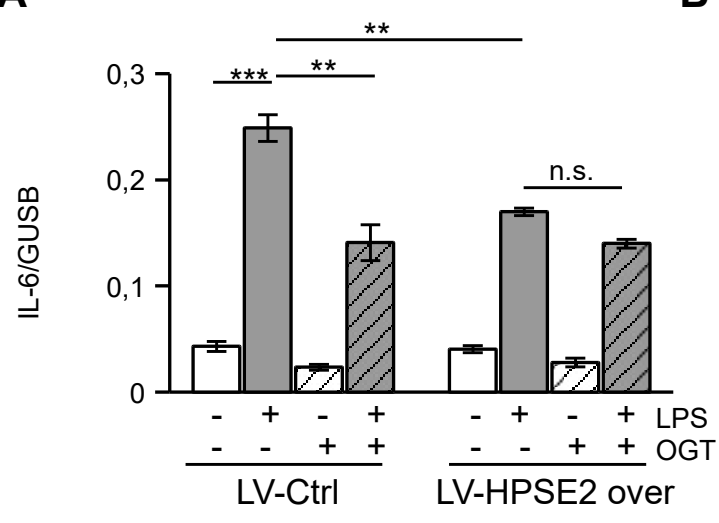

B

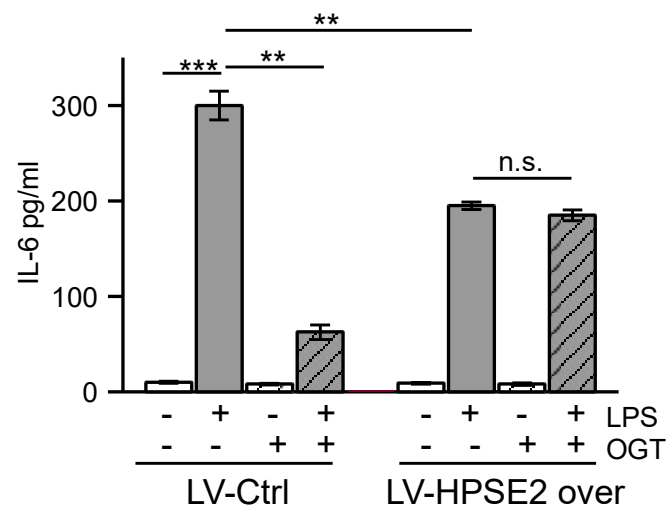

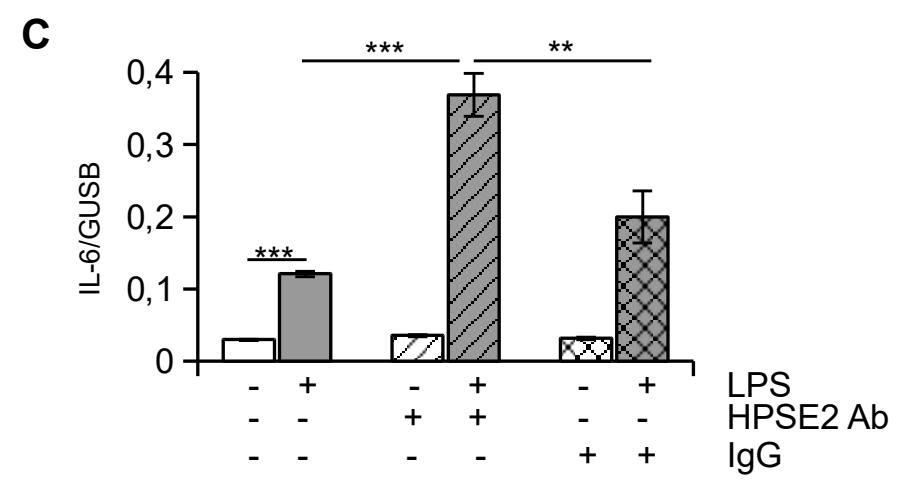

Figure 4. HPSE2 prrevents HPSE1 activity. A. Endothelial cells were pre-treated with inhibitor of HPSE1 catalytic activity, OGT 2115, and then stimulated with $100 \mathrm{ng} / \mathrm{ml}$ LPS for $3 \mathrm{hrs}$ (A) and overnight (B). IL-6 expression was analyzed by RT-PCR (A) and ELISA (B). C. Endothelial cells were pre-incubated with mouse IgG or anti-HPSE2 antibody $1 \mathrm{c} 7$ for 30 min prior to LPS stimulation and then stimulated with 100 $\mathrm{ng} / \mathrm{ml}$ LPS for 3 hrs. IL-6 expression was assessed by RT-PCR. 
A

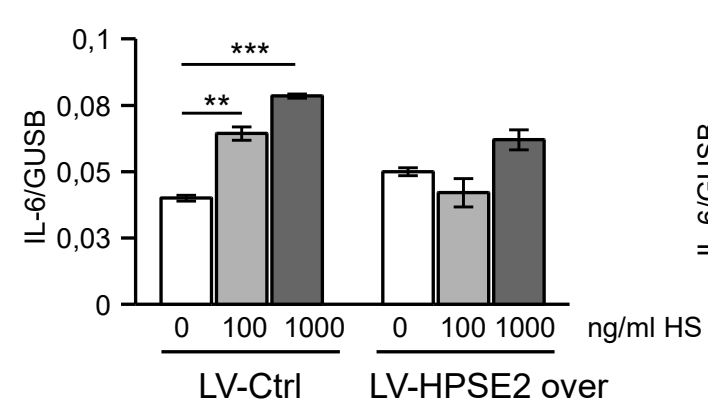

C

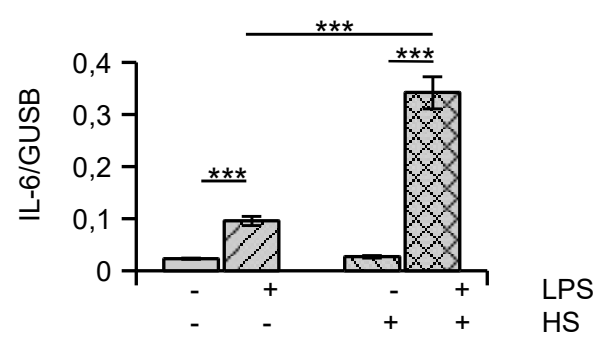

B
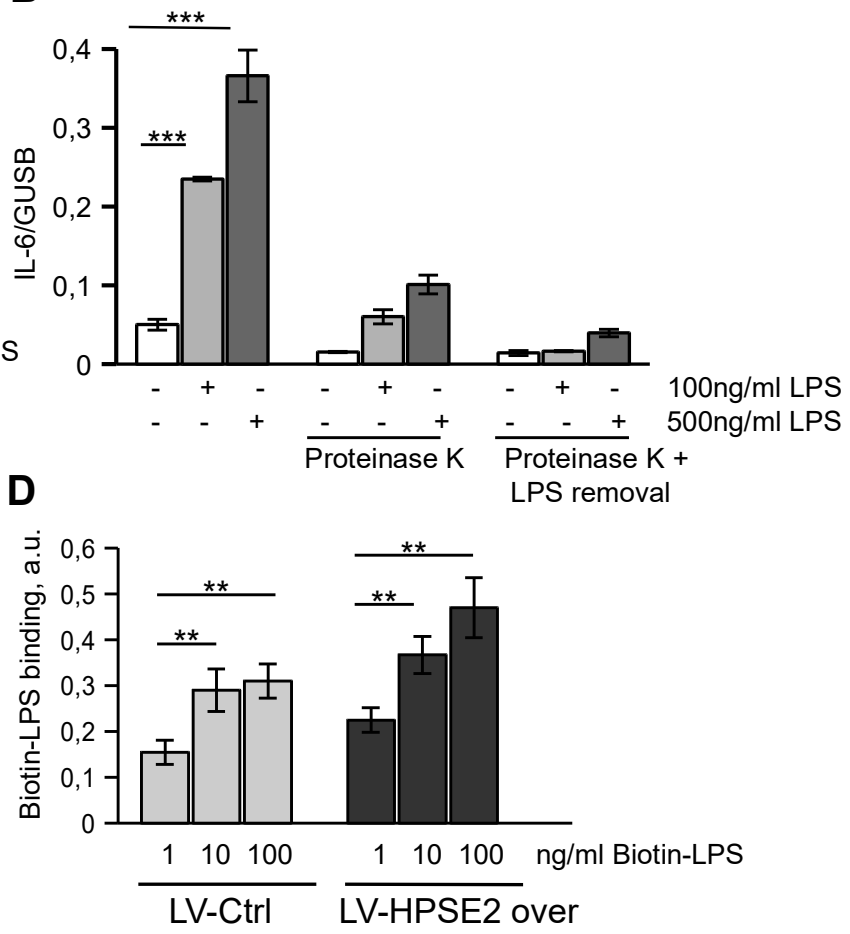

Figure 5. Heparan sulfate fragments cause weak activation of endothelial cells. A. Endothelial cells were treated with the indicated concentration of heparan sulfate (HS) for $3 \mathrm{hrs}$. IL-6 expression was assessed by RT-PCR. B. Conditioned medium of endothelial cells treated for $3 \mathrm{hrs}$ with $100 \mathrm{ng} / \mathrm{ml}$ and $500 \mathrm{ng} / \mathrm{ml} \mathrm{LPS}$ was used for stimulating naïve cells. Conditioned medium was treated with Proteinase K immobilized on agarose beads and remaining LPS was removed by incubation with LPS removal beads, as indicated. IL-6 expression was assessed by RT-PCR. C. Endothelial cells were stimulated with $100 \mathrm{ng} / \mathrm{ml} \mathrm{LPS} \mathrm{in} \mathrm{the}$ absence and in the presence of $100 \mathrm{ng} / \mathrm{ml}$ heparan sulfate (HS). D. Cell-based ELISA for Biotin-LPS binding. Lentivirus-transduced endothelial cells were incubated on ice for $1 \mathrm{~h}$ in the presence of biotin-LPS as indicated. After washing cells were incubated with SV-HRP. Biotin-LPS binding was quantified using TMB substrate kit. 
A

\section{B}

Pull-down: Biotin-LPS

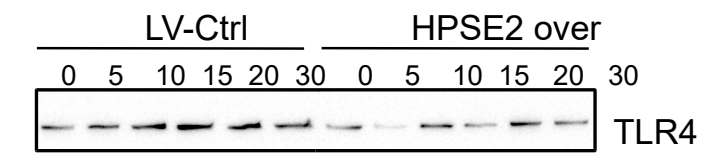

Loading

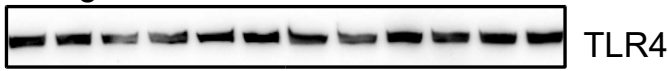

D
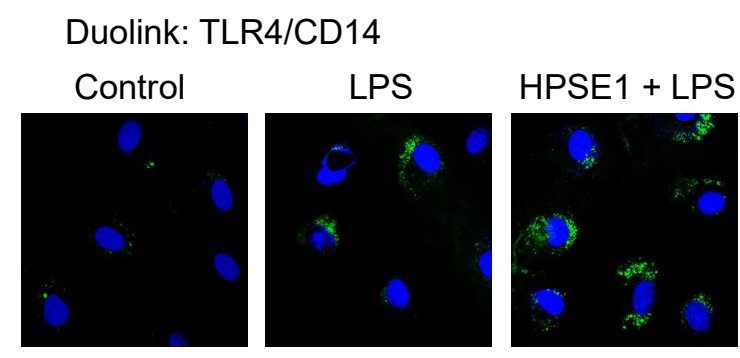

Cell surface TLR4

$\mathbf{F}$

LV-HPSE2 over
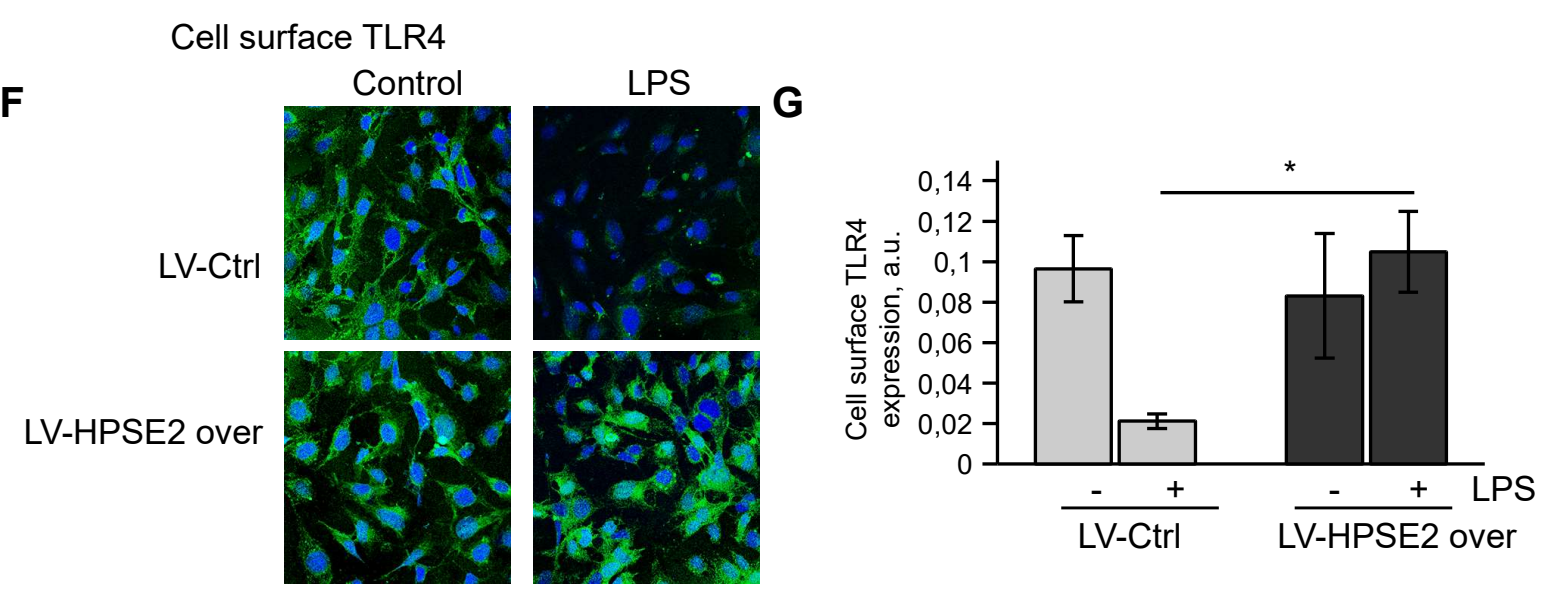
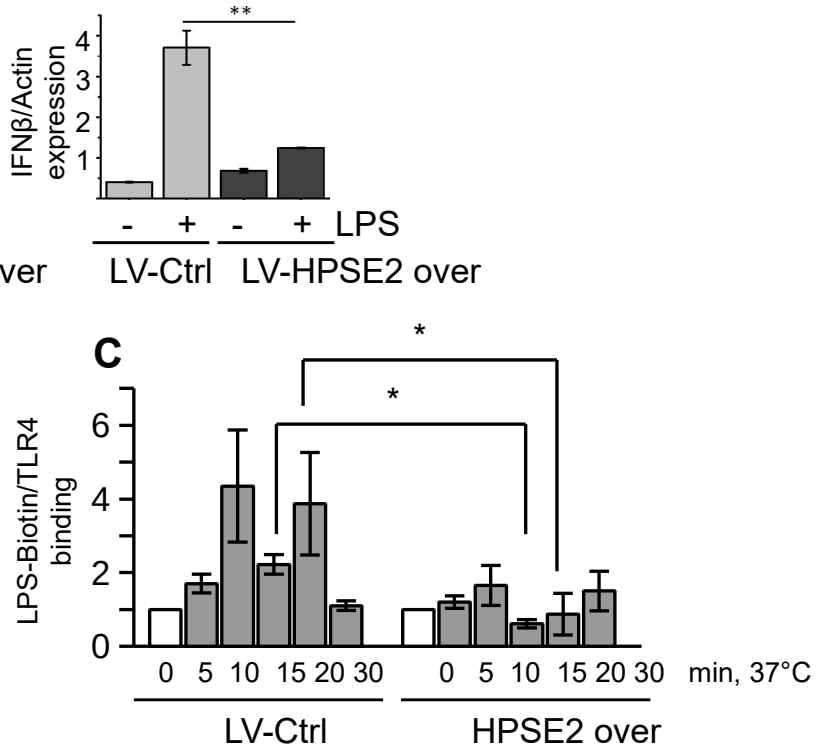

E

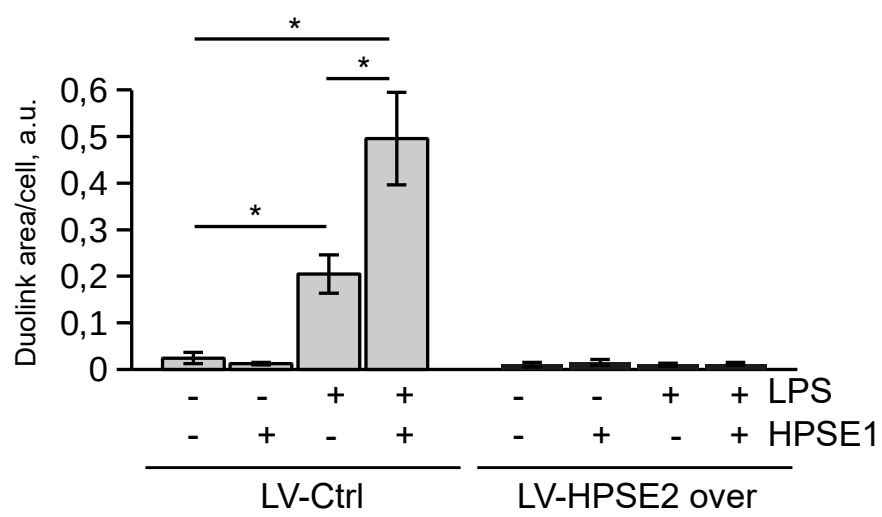

Figure 6. HPSE2 overexpression prevents TLR4 activation by LPS. A. Endothelial cells infected with Control and HPSE2 overexpression lentivirus were treated with $100 \mathrm{ng} / \mathrm{ml}$ LPS for $3 \mathrm{hrs}$. Expression was analyzed by TaqMan RT-PCR. B. TLR4 pull-down using biotin-LPS was performed as described in the Materials and Methods section. TLR4 was detected by immunoblotting. C. Quantification of independent TLR4 pull-down assay experiments. D. Duolink proximity ligation assay revealing direct interaction of TLR4 and CD14 was performed on endothelial cells stimulated with $100 \mathrm{ng} / \mathrm{ml}$ LPS for $20 \mathrm{~min}$. Treatment with catalytically active HPSE1 was performed for $1 \mathrm{~h}$ prior to LPS stimulation. E. Duolink signal stained as in F was quantified using ImageJ as described in Materials and Methods. F. To detect cell surface TLR4 lentivirus-infected endothelial cells were stimulated with $500 \mathrm{ng} / \mathrm{ml}$ LPS for $1 \mathrm{~h}$, then placed on ice and incubated with TLR4 antibody. Then, the cells were washed, fixed, and stained with secondary antibody (green) and DAPI. G. Cell surface TLR4 expression of lentivirus-infected and LPS-stimulated endothelial cells was quantified using cell-based ELISA as described in Materials and Methods. 
A

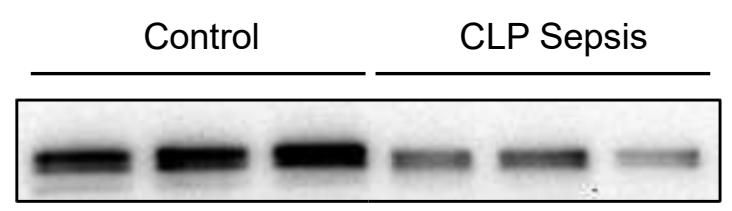

\footnotetext{
C
}
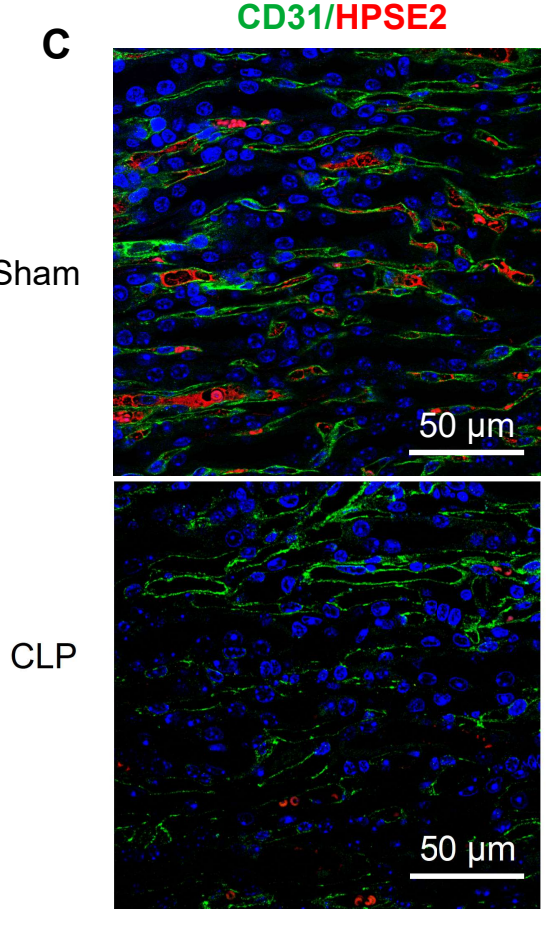

$\mathbf{E}$

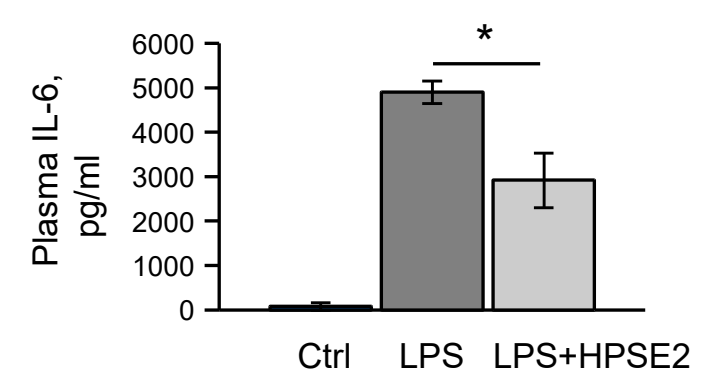

B
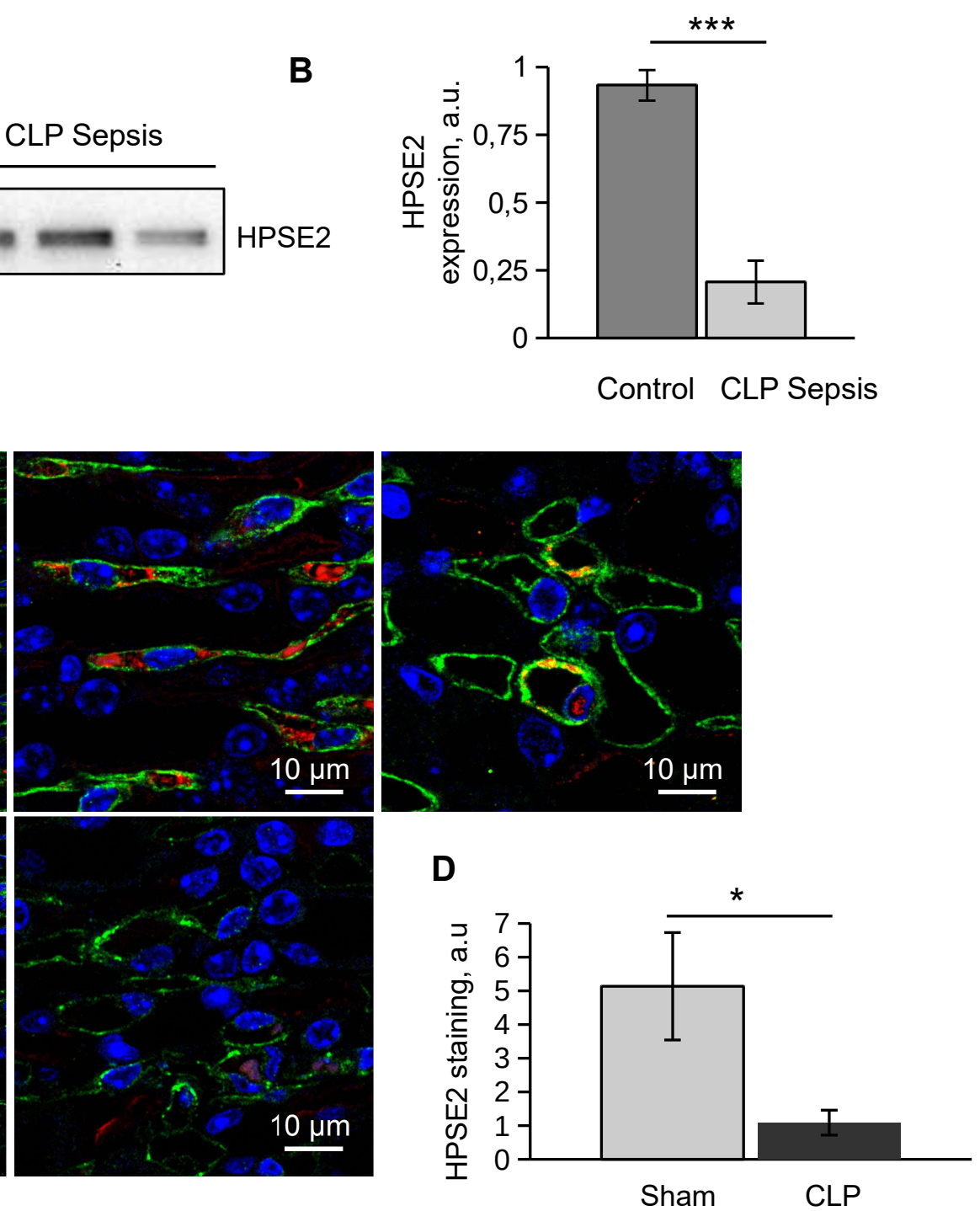

$\mathbf{F}$

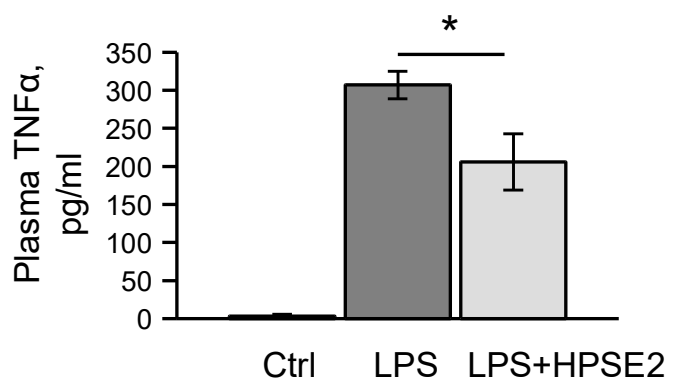

Figure 7. HPSE2 protects against inflammation in vivo. A. Serum level of HPSE2 expression in mouse CLP sepsis model was assessed by western blotting. B. Qantification of westernblotting data. C. Expression of HPSE2 in mouse kidney medullary capillaries in CLP sepsis model. Tissue sections were stained with CD31(Alexa 488) and HPSE2 (Alexa 594). Nuclei were stained with DAPI. D. Quantification of HPSE2 immunohistochemistry stainings in mouse kidney. E, F. Mice were iv injected with $5 \mu \mathrm{g} / \mathrm{g}$ body weight LPS alone or LPS alone with $5 \mu \mathrm{g} / \mathrm{g}$ body weight purified HPSE2. After $2 \mathrm{hrs}$ plasma cytokine level was measured using cytometric bead array. (E) IL-6 expression; (F) TNF $\alpha$ expression. Mean \pm s.e.m. is shown. 